\title{
Application of Nanoparticles in Quartz Crystal Microbalance Biosensors
}

\author{
Somayeh Heydari*, Gholam Hossein Haghayegh \\ Faculty of Agriculture, Higher Education Complex of Torbat-e Jam, Torbat-e Jam, Iran \\ Email: so heydari_83@yahoo.com, Gholamhosseinh23@gmail.com
}

Received 24 April 2014; revised 23 May 2014; accepted 23 June 2014

Copyright (C) 2014 by authors and Scientific Research Publishing Inc.

This work is licensed under the Creative Commons Attribution International License (CC BY).

http://creativecommons.org/licenses/by/4.0/

(c) (i) Open Access

\begin{abstract}
Nanoparticles are playing an increasingly important role in the development of biosensors. The sensitivity and performance of biosensors are being improved by using Nanoparticles for their construction. The use of these Nanoparticles has allowed the introduction of many new signal transduction technologies in biosensors. In this report, a comprehensive review of application of nanoparticles in Quartz Crystal Microbalance biosensors is presented. The main advantages of QCM in sensing fields include high sensitivity, high stability, fast response and low cost. In addition, it provides label-free detection capability for bio-sensing applications. Firstly, basic QCM's design and characterization are described. Next, QCM biosensors based on modification of quartz substrate structure and their applications are digested. Nanoparticles and their utilizationin analysis are then illustrated. These include Nanoparticles in bio applications that cover Nanoparticles in Quartz Crystal Microbalance biosensors.
\end{abstract}

\section{Keywords}

Nanoparticles, Quartz Crystal Microbalance, QCM, Biosensors, Review

\section{Introduction}

Nanoparticle analysis is a rapidly growing research area with applications in a variety of fields including energy, nanocomposite materials, the environment and healthcare. Nanoparticles are being incorporated into materials such as solar panels, nanomachines, and a variety of thin films and coatings to generate more desirable properties. Between the different applications, the use of NPs for biosensing is showing an increased interest for several areas such as clinical analysis [1] [2], environmental monitoring [3]-[5] as well as safety and security. NPs involvements in DNA, protein and even cell sensing systems have recently been the hottest topics in nanobio-

"Corresponding author. 
technology. Although their use and benefits are unquestioned, there are still potential risks in their widespread use to health and the environment. Therefore, there is a need for new techniques for characterizing nanoparticles including their interactions with surfaces, each other and their stability in the environment. Quartz Crystal Microbalance (QCM) is an analytical technique that provides in-situ analysis of interactions taking place at surfaces. The main advantages of QCM in sensing fields include high sensitivity, high stability, fast response and low cost. In addition, it provides label-free detection capability for bio-sensing applications. Being labeled free, it dispenses with the time and cost demanding labeling step, and also eliminates any possible interference of the "true" binding process due to the presence of the labels. Given the special importance of bio analysis, we intend in this review to overview some of the major advances and milestones in the field of Quartz Crystal Microbalance biosensors based on NPs underlying the different approaches reported so far. Since the nanoparticles and biomolecules typically meet at the same nanometer length scale, this interdisciplinary approach will contribute to the establishment of a novel field, descriptively termed immunosensing nanotechnology or nanoimmunosensing. NP based immunosensing systems are proving to assist in the development of new and versatile protein detection methods.

In this report, firstly, basic QCM's design and characterization are described. Next, QCM biosensors based on modification of quartz substrate structure and their applications are discussed. Nanoparticles and their applications in analysis are then illustrated. These include nanoparticles in bio applications that cover nanoparticles in Quartz Crystal Microbalance biosensors.

\section{Quartz Crystal Microbalance}

Piezoelectricity is defined as electric polarization produced by mechanical strain in certain crystals, the polarization being proportional to the strain [6]. The Curies first observed piezoelectricity in 1880 as a potential difference generated across two surfaces of a quartz crystal under strain [7]. The converse piezoelectric effect, the deformation of apiezoelectric material by an applied electric field, was predicted by Lippman [8]. Thus, when a thin wafer from a piezoelectric crystal such as quartz is placed in an alternating electric field of the right frequency it will oscillate in a mechanically resonant mode of the wafer. The resonance frequency depends upon the angles with respect to the opticalaxis at which the wafer was cut from a single crystal and inversely on the crystal thickness. Quartz Crystal Microbalance (QCM) devices derive from piezoelectric quartz crystal resonators that resonate electromechanically in a thickness-shear mode (TSM) (Figure 1, Figure 2). Owing to piezoelectric effects, the resonant properties of crystal can be influenced by external physical loading, which may be classified into two main types, gravimetric and viscoelastic loading. In the first case, gravimetric force due to mass rigidly deposited on the crystal surface is balanced by a force originating from the shear gradient inside the crystal, leading to the resonance frequency shift $\left(\Delta f_{g}\right)$, which is governed by Sauerbrey's equation [10] [11]:

$$
\begin{gathered}
\Delta f_{g}=-\frac{2 f_{0}^{2}}{\sqrt{\rho_{q} \mu_{q}}} \frac{\Delta M}{A} \\
f_{0}=\frac{v}{2 t_{q}}=\frac{\sqrt{\left(\mu_{q} / \rho_{q}\right)}}{2 t_{q}}
\end{gathered}
$$

where $f_{0}$ is the fundamental resonance frequency, $\Delta M$ is the mass deposited on QCM surface, $A$ is the active electrode area, $v$ is the acoustic wave velocity, $\rho_{q}$ is the density of crystal (2.648 $\mathrm{g} \cdot \mathrm{cm}^{-3}$ for quartz), $\mu_{q}$ is the shear modulus of the cut face $\left(2.947 \times 10^{11} \mathrm{~g} \cdot \mathrm{cm}^{-1} \cdot \mathrm{s}^{2}\right.$ for AT-cut quartz $)$ and $t_{q}$ is the crystal thickness. With this loading effect, QCM has been routinely used for thickness monitoring in physical vapor deposition processes.

For the viscoelastic loading, resonance frequency is changed due to acoustic-fluid damping interaction when QCM operates in viscoelastic medium such as liquid [12]. Unlike gravimetric loading, there are large changes of dissipation factor and resonant resistance due to energy losses of shear wave that travels through non-rigidly adsorbed layers [13]-[16]. The viscoselastic resonance frequency shift $\left(\Delta f_{v}\right)$, dissipation factor change $(\Delta D)$ and resonant resistance change $(\Delta R)$ are given by:

$$
\Delta f_{v}=-f_{0}^{3 / 2} \sqrt{\frac{\eta_{L} \rho_{L}}{\pi \mu_{q} \rho_{q}}}
$$




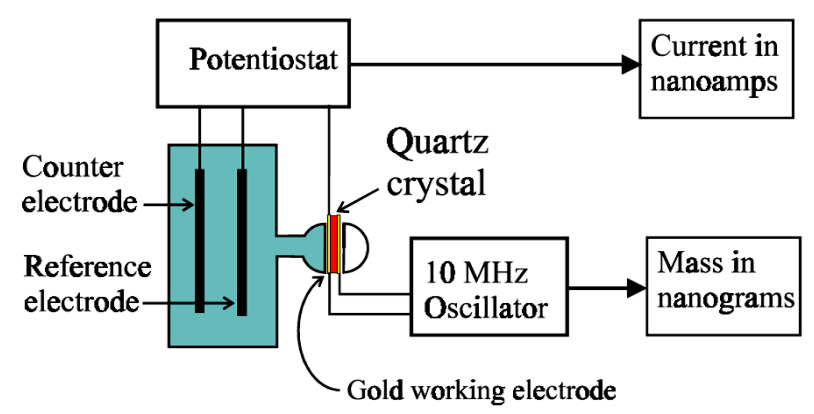

Figure 1. Schematic diagram of Quartz Crystal Microbalance instrumentation. (Crystal is held between two o-rings) Reproduced with permission from Ref. [7], Copyright 2008 Elsevier.

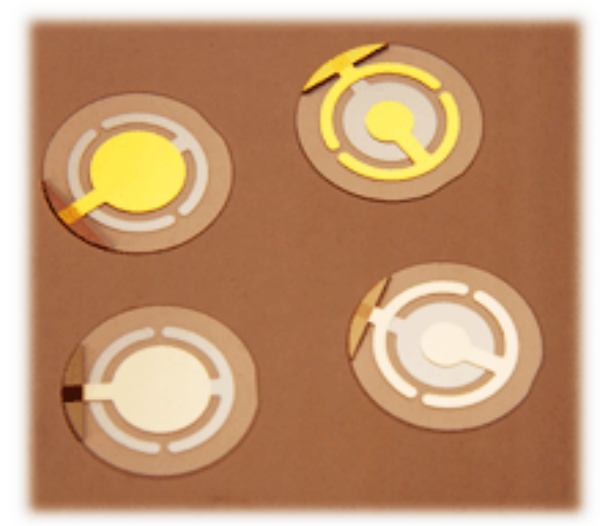

Figure 2. Crystals used in a QCM. Reproduced with permission from Ref. [9], Copyright 2004 Elsevier.

$$
\begin{gathered}
\Delta D=2 f_{0}^{1 / 2} \sqrt{\frac{\eta_{L} \rho_{L}}{\pi \mu_{q} \rho_{q}}} \\
\Delta R=\frac{\left(2 \pi \eta_{L} \rho_{L} f_{0}\right)^{1 / 2} A}{k^{2}}
\end{gathered}
$$

where $\rho_{L}, \gamma_{L}$ and $k$ are viscosity, density and electromechanical coupling factor of the liquid medium, respectively. Both dissipation factor and resonant resistance can be directly measured experimentally. The combined measurements of frequency shift and changes in the dissipation factor and resonant resistance have been termed, QCM-D and QCM-R, respectively [17]. With the combined mass and viscosity-density effects, QCM can be applied for bio/chemical sensing by coating with a chemically or biologically sensitive film to sense very small amount of adsorbed gases such as volatile organic compounds (VOCs) [18] [19] and environmental pollutants [20]-[22] and liquid phase biochemicals.

A quartz crystal microbalance (QCM) measures a mass per unit area by measuring the change in frequency of a quartz crystal resonator. The resonance is disturbed by the addition or removal of a small mass due to oxide growth/decay or film deposition at the surface of the acoustic resonator. The QCM can be used under vacuum, in gas phase ("gas sensor", first use described by King) [23] and more recently in liquid environments. It is useful for monitoring the rate of deposition in thin film deposition systems under vacuum. In liquid, it is highly effective at determining the affinity of molecules (proteins, in particular) to surfaces functionalized with 3 to investigate interactions between biomolecules [24]-[28].

There has been a rapid increase in the number of publications related to QCM sensing applications during the last few decades (Figure 3). QCMs have been used for multifarious applications in various disciplines of science and technology for the detection of metals in vacuum, vapors, chemical analytes, environmental pollu- 


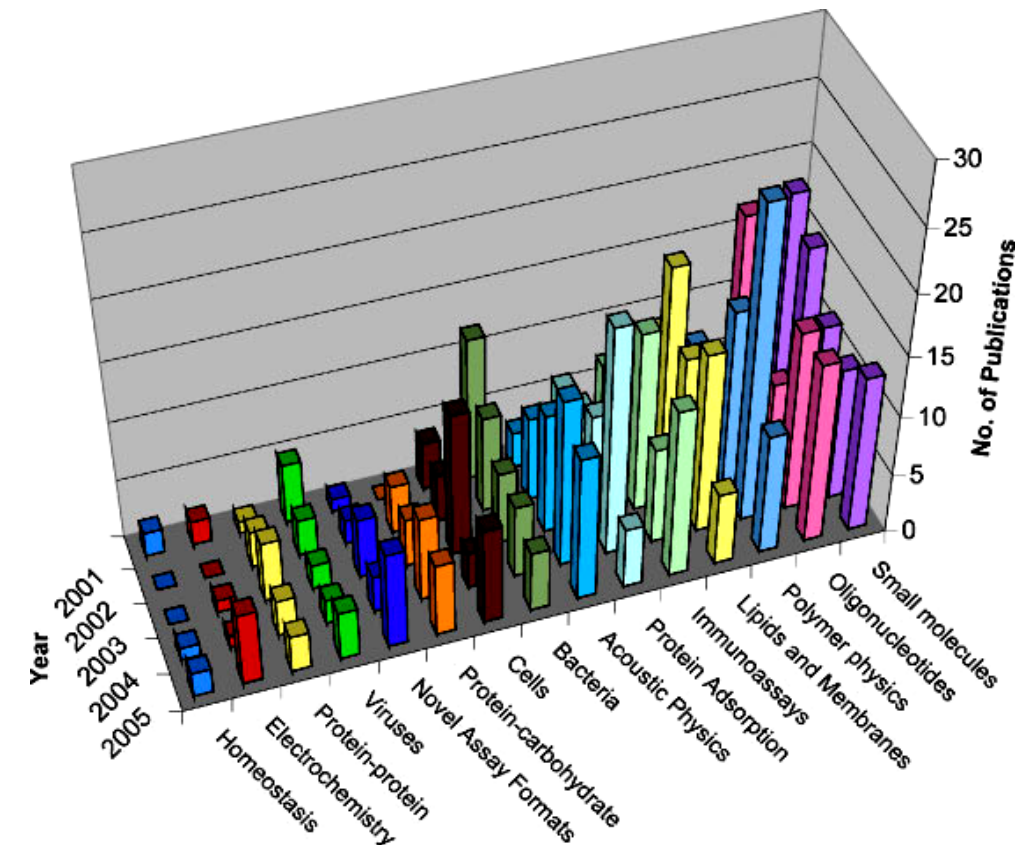

Figure 3. A summary of the number of papers (for specific analytes by class) referencing "QCM" in the title, Keywords or Abstract [29]. Reproduced with permission from Ref. [29], Copyright 2007 John Wiley \& Sons, Ltd.

tants, biomolecules, disease biomarkers, cells, and pathogens. They are also employed for deposition rate monitoring, electrochemical deposition, corrosion studies, detection in gas chromatography, and controlling thickness and composition of sputtered materials. Presently, there are several companies that are dealing with QCM-based systems.QCM provides one of the most promising sensor technology based on its low cost, rapid response, portability, nonhazardous label-free real-time procedure, and high sensitivity, which is ideal for the sensitive online detection of analytes and holds a great promise for the next-generation sensors.

\section{QCM as a Biosensor}

Nowadays the applications of sensors are a very promising research field since they find application in many different areas [30]-[35]. Biosensors are an increasingly important technology in the detection of compounds ranging from pesticides to biological weapons. Typically, biosensors consist of a biological macromolecule that is immobilized on the surface of a signal transducer, as shown in Figure 4. As the macromolecule binds specifically to the ligand being detected, the signal transducer can measure a physical change due to the binding event. The transducer usually detects a change in resistance, $\mathrm{pH}$, heat, light, or mass and then converts that data to an electrical signal to be collected and processed. One promising type of detector is the Quartz Crystal Microbalance (QCM). The QCM is a piezoelectric mass-sensing device. A QCM device works by sending an electrical signal through a gold-plated quartz crystal, which causes a vibration at some resonant frequency. The QCM then measures the frequency of oscillation in the crystal. When used as a biosensor, the QCM can detect changes in frequency of the crystal due to changes in mass on the surface of the crystal.

The sensitivity and specificity of QCM-based biosensors is dependent on the immobilization of recognitionlayer. For example various strategies have been employed for the immobilization of antibodies on the crystal surface. Passive adsorption of antibodies has been the most widely used method. However, it leads to random immobilization of antibodies on the surface, which may not be in functionally active orientation. The crystallizable fragment $(\mathrm{Fc})$-binding proteins such as protein $A$, protein $\mathrm{G}$ and protein $\mathrm{A} / \mathrm{G}$ are employed for oriented immobilization of antibodies on the gold-coated QCM surface such that their antigen binding sites (Fab region) are completely free for binding antigens. Another strategy employs the initial generation of amino groups on the QCM surface by treatment with 3-aminopropyltriethoxysilane followed by the activation of amine-functionalized surface with glutaraldehyde to generate aldehyde groups, which bind to the antibody through its amino groups. 


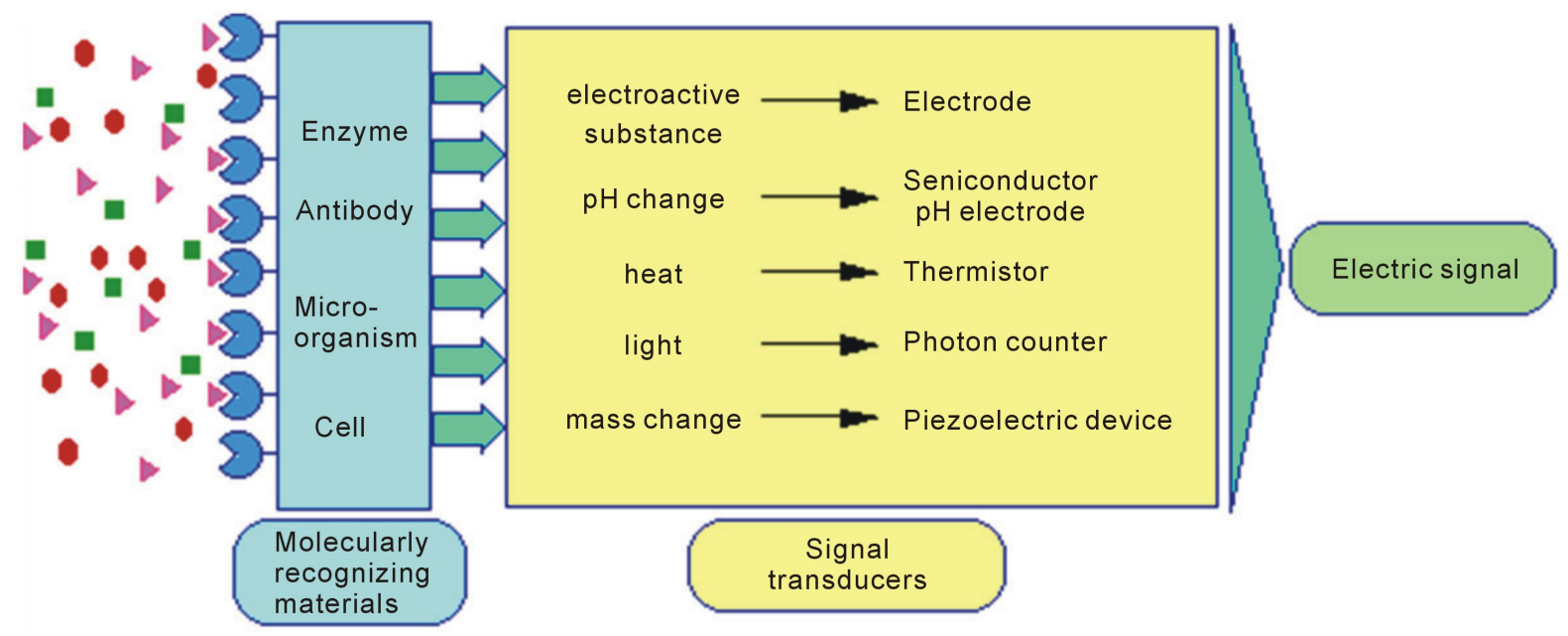

Figure 4. Schematic for generic biosensor [36].

The interactions between thiols and gold are very strong and have also been exploited for antibody binding by employing self-assembled layers of thiols and sulphides. The avidin-biotin interactions have also been employed, where the avidin/streptavid in-coated QCM-gold-surface is bound to the biotinylated antibody. Other approaches based on the use of polyelectrolytes, polymers, and Langmuir-Blodgett films have also been used.

QCM biosensors have been employed in the label-free detection of an incredibly broad range of analytes; from interfacial chemistries and lipid membranes to small molecules and whole cells [37]. They provide a unique method for observing in situ events involving "soft matter", in which changes in contact mechanics, interfacial dynamics, surface roughness, viscoelasticity, density and mass can be monitored in real time [38]-[44]. This level of information content goes beyond that produced by many more widely adopted optical techniques that are used to analyse molecular changes occurring in biochemical processes. Acoustic sensor technology is thus highly interdisciplinary and has encompassed advances and improvements from electrical engineers to cell biologists. Braunhut et al. adapted the Quartz Crystal Microbalance (QCM) biosensor technique to study responses of human mammary epithelial tumor cells to taxanes [45]. Taxanes are used for the treatment of many human cancers, as first- and second-line chemotherapeutics.

The ultimate goal in any biosensor development project is its use for actual sample detection. Recently, there has been an interest in biosensors with aptamers as bio-recognition elements, but reported examples all deal with standards, not human serum. In comparison to antibodies, aptamer receptors have a number of advantages. The main advantage is the avoidance of the use of animals for their production. Moreover, the aptamer select ion process can be manipulated to obtain aptamers that bind to a specific region of the target and with specific binding properties under different binding conditions [46]-[50]. In order to verify the differences of aptamer-based biosensor and antibody-based biosensor in clinical detection, Yao et al. carried out a comparison of the performance of aptamer-based and antibody-based Quartz Crystal Microbalance (QCM) biosensors for the detection of immunoglobulin E (IgE) in human serum [51]. Wu et al. developed a DNA piezoelectric biosensing method for real-time detection of Escherichia coli O157:H7 in a circulating-flow system [52]. The QCM system was also applied in the detection of PCR-amplified DNA from real samples of E. coli O157:H7. The resultant H\% of the PCR-amplified double-strand DNA was comparable to that of the synthetic target T-104AS, a single-strand DNA. The piezoelectric biosensing system has potential for further applications. This approach lays the groundwork for incorporating the method into an integrated system for rapid PCR-based DNA analysis.

\section{Nanoparticles}

One of the most important functions of nanoparticles is catalysis, especially with noble metal nanoparticles, which have high catalytic activity for many chemical reactions. Because nanomaterials also have good biocompatibility, they are used to immobilize biomolecules for the fabrication of biosensors. Sensitivity and other attributes of biosensors can be improved by using nanomaterials in their construction. Nanomaterials, or matrices with at least one of their dimensions ranging in scale from 1 to $100 \mathrm{~nm}$, display unique physical and chemical 
features because of effects such as the quantum size effect, mini size effect, surface effect and macro-quantum tunnel effect.

\subsection{Nanoparticles in Bio Applications}

Nanoparticles have numerous possible applications in biosensors. For example, functional nanoparticles (electronic, optical and magnetic) bound to biological molecules (e.g. peptides, proteins, nucleic acids) have been developed for use in biosensors to detect and amplify various signals. Some of the nanoparticle-based sensors include the acoustic wave biosensors, optical biosensors, magnetic and electrochemical biosensors. The structure of IgG, the most used antibody in immunosensig assays, has been determined by X-ray crystallography (Figure 5(a), upper part) which shows a Y-shape form consisting of three equal-sized portions, loosely connected by a flexible tether [53]. The antibodies are constituted by two heavy and two light polypeptide chains linked between themas shown in Figure 5(a) (lower part). The $\mathrm{C}$ regions determine the isotype of the antibody whereas the variable regions of one heavy and one light chain constitute an Antigen Binding Site (ABS). The digestion of antibody with papain (Figure 5(b) upper part) and pepsin (Figure 5(b) lower part) proteases produces several smaller fragments that may be used instead of the original antibody for immunosensing applications. Immunoassays are based on the interaction between the antibody and the antigen, in particular between the ABS and the epitope. In fact this interaction gives high specificity and sensitivity to the immunoassay. In order to functionalize the Ig, the connection of labels through three main groups: $-\mathrm{NH}_{2},-\mathrm{COOH}$ and $-\mathrm{SH}$ have been performed. Figure 5(c) (upper part) shows two examples of conjugation of mono-sulfo-NHS-AuNPs with an antibody through the amino group. A conjugation of monomaleimido Au NPs (Figure 5(c), lower part) with an antibody, through the $-\mathrm{SH}$ group, is also shown. The use of the thiol group for the functionalization is a good way to control the direction of the bond between the label and the antibody, and prevent the involvement of the ABS. Figure 5(d) is an example of conjugation through the carboxyl group reported by Ahirwal et al. [54]. They connected the carboxi-term of the antibody with an AuNP by glutathione used as aspacer. The C-term region is a good point to attach the label, since it $\mathrm{s}$ far from the ABS and should allow the molecule interaction with the antigen. The AuNP modification with protein can even be observed by TEM (Figure 5(e)) [55].

\section{Nanoparticles in Quartz Crystal Microbalance Biosensors}

Quartz crystal microbalances have emerged in the last few years as versatile biosensors demonstrating remarkable achievements such as high sensitivity and label free detection [56]-[58]. In the quartz crystal microbalance, the bioreaction generates a change in the mass, reordering the charges in the surface of the piezoelectric material and giving rise to a change in the resonant frequency of the microbalance. The use of NP labels in sandwich assays can increase both the surface stress and the mass of the immune complex, allowing for the increase in sensitivity of these electromechanical assays. This was the case in work reported for the detection of human IgG [59] and aflatoxin B1 [60] at clinical relevant levels using AuNPs as amplification agents in adynamic mode quartz crystal microbalance biosensor.

Quartz crystal microbalance biosensors were developed to greatly improve the sensitivity and limits of detection [61]. In the mass-amplified quartz crystal microbalance assay variant of this technology, antibody modified sol particles indirectly bind to an electrode surface by complexing to an analyte that has been itself captured by an antibody immobilized on the electrode surface. The large mass of the bound sol particles greatly affects the vibrational frequency of the quartz crystal and this is used as the basis for detection. The assay can be carried out in the competitive mode. The preferred diameter of sol particles is in the range of $5-100 \mathrm{~nm}$. Other high-density particles (e.g. Au, Pt, CdS, $\mathrm{TiO}_{2}$, polymers) may be also suitable [62] [63].

Recently Chu et al. developed a label-free gliadinimmuno sensor by applying $25 \mathrm{~nm}$ gold nanoparticles (AuNPs) to the surface of a bare QCM electrode [64]. Also a rapid and sensitive Quartz Crystal Microbalance (QCM) biosensor combined with gold nanoparticle amplification for diagnosis Mycobacterium tuberculosis was developed by Kaewphinit et al. [65]. The label free QCM was successfully developed with high sensitivity, specificity, low cost and convenience, this technique may prove to be a powerful tool for an early diagnosis of $M$. tuberculosis.

DNA-conjugated nanoparticles can be used to enhance the signal produced upon hybridization to a surface-bound single-stranded template [66]-[73]. They can also be used to increase the surface area available to immobilize the DNA template on a sensor [74]-[76]. Detection sensitivity is generally in the region of $10^{-15}-10^{-16} \mathrm{M}$, with one report of zeptomolar $\left(10^{-21} \mathrm{M}\right)$ quantities of specific nucleic acid [77]. Ma et al. [78] 
(a)
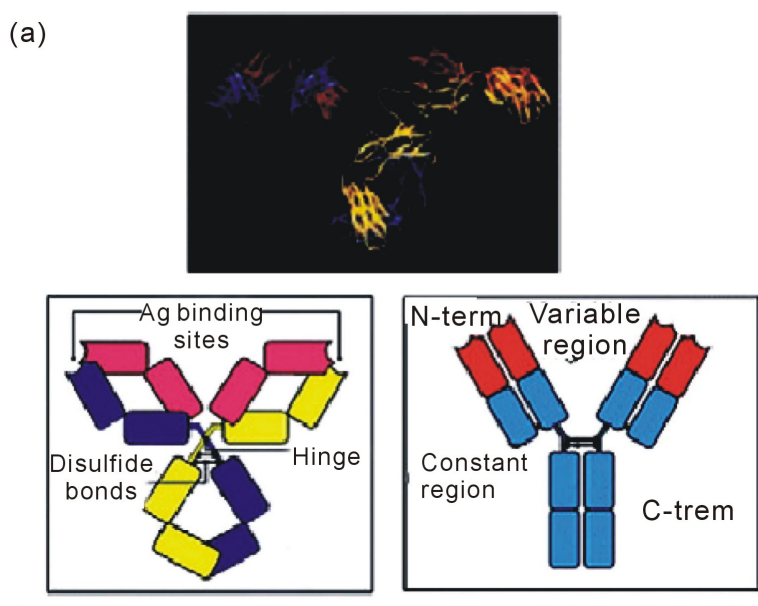

(c)

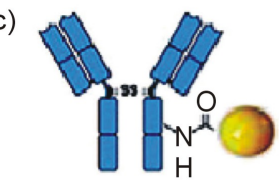

(i) Reduction

(Ii) Monomale Nanogold

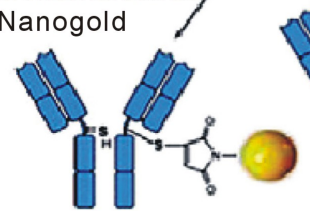

(b)

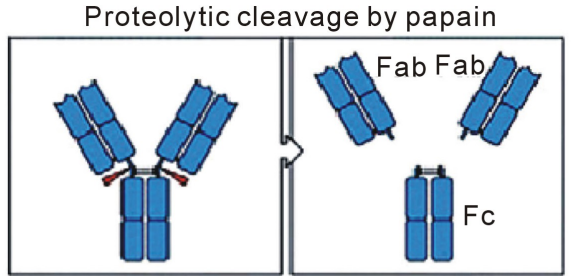

Proteolytic cleavage by pepsin

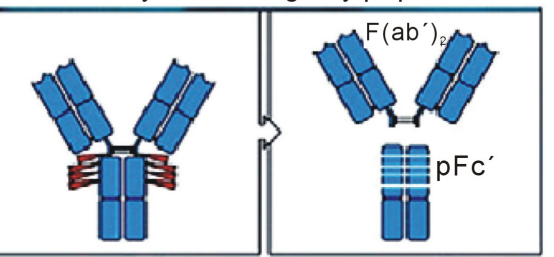

(d)

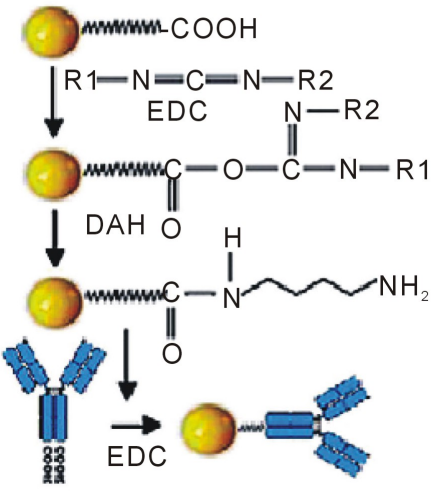

(AuNP)

(EDC Activated AuNP'S)

(AuNP/DAH)

(AuNP-Antobody conjugate)

(e)
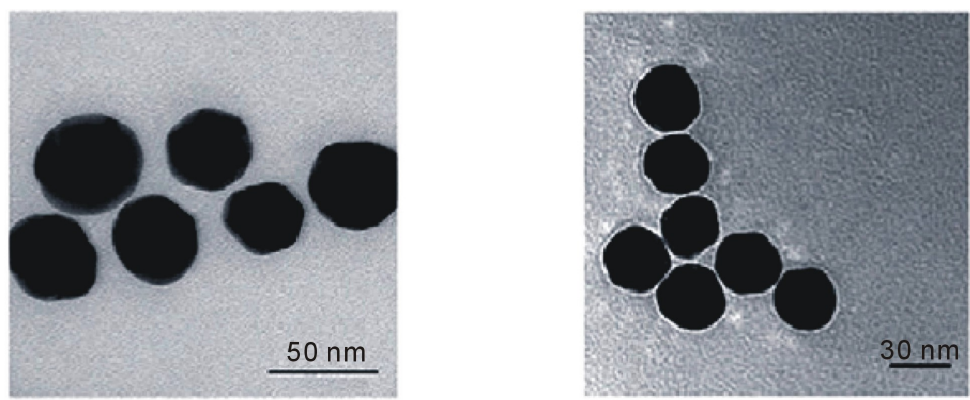

Figure 5. (a) X-ray crystallographic structure of an IgG antibody (upper part); A schematic representation of IgG and a simplified scheme of the antibody's structure (lower part); (b) The papain (upper part) and the the pepsin (lower part) cleavages; (c) Functionalization of a whole IgG or a Fab by a Mono-Sulfo-NHS-AuNP viafree amino groups (upper part); monomaleimidoAuNP binds the $\mathrm{S}$ atom after the reduction of the disulfide bond starting from the whole IgG (lower part, left) or from $\mathrm{F}(\mathrm{ab})_{2}$ (lower part, right) [53]; (d) An activated by EDC AuNP coated with gluthatione, as spacer arm, reacts with an IgG, also activated by EDC [54]; (e) TEM images ofAuNPs (left part) and AuNPs conjugated with IgG (right part). Image shows a thin white layer, called "halo" effect, surrounding the surface of the AuNPs indicatingcoating with protein. Reproduced with permission from Ref. [55], Copyright 2010 Elsevier.

used a mixture of $\mathrm{HAuCl}_{4}$ and $\mathrm{NH}_{2} \mathrm{OH}$ to enlarge the gold particles. However, it has been shown that $20 \mathrm{~nm}$ is the optimal particle size for maximally increasing the sensitivity as the larger particles suffer from weaker binding to the surface and are therefore lost on exposure to flow [71]. A quartz crystal microbalance (QCM) DNA sensor, based on the nanoparticle amplification method, was developed for detection of Escherichia coli O157:H7 [79]. A thiolated single-stranded DNA (ssDNA) probe specific to E. coli O157: H7 was immobilized onto the QCM sensor surface through self-assembly (Figure 6). The hybridization was induced by exposing the ssDNA probe to the complementary target DNA, and resulted in the mass change and therefore frequency 


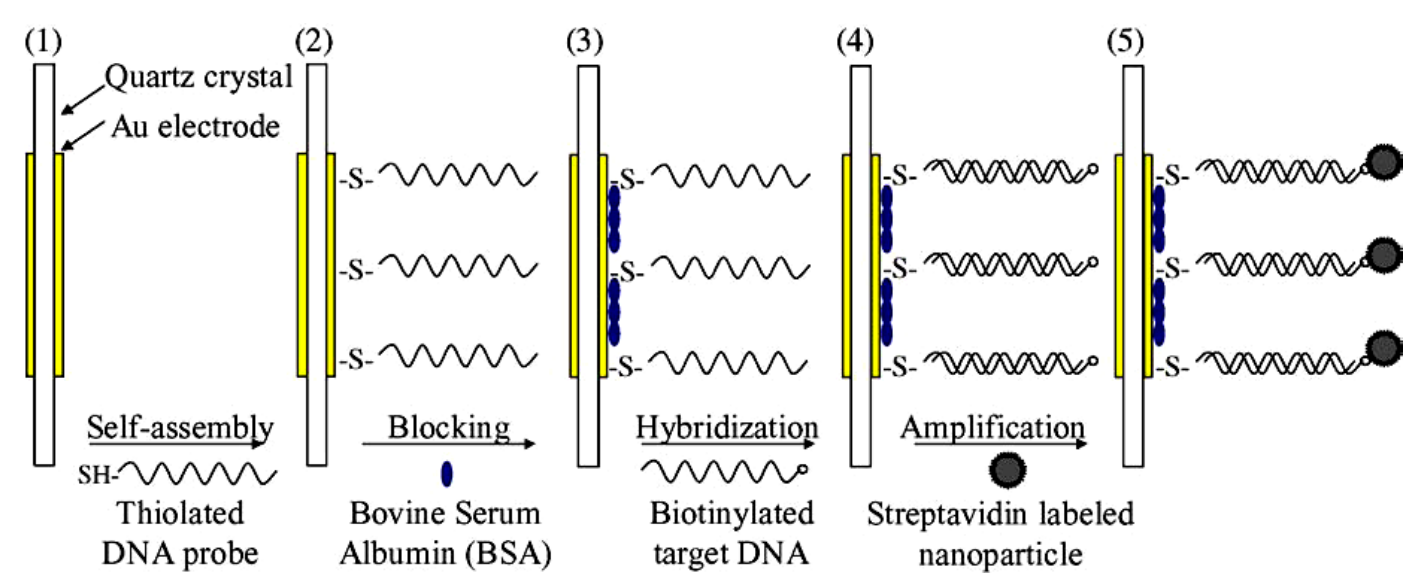

Figure 6. Llustration of the sensor fabrication and detection procedure reproduced with permission from Ref. [79], Copyright 2006 Elsevier.

change of the QCM.

The enhancement of a single strain DNA probe linked to the sensor surface is of crucial importance in DNA molecule recognition. By means of nanogold modification of the sensor surface in addition to the nanogold amplifier, DNA detection sensitivity higher than $10^{-16} \mathrm{~mol} / \mathrm{L}$ was obtained in a Quartz Crystal microbalance (QCM) system, much higher than the ordinary QCM sensor without surface modification by nanogold (Figure 7) [63].

Recently a DNA probe functionalized quartz crystal microbalance (QCM) biosensor was developed to detect B. anthracis based on the recognition of its specific DNA sequences, i.e., the 168 bp fragment of the Ba813 gene in chromosomes and the $340 \mathrm{bp}$ fragment of the paggene in plasmid pXO1 [80]. Willner et al. described three different methods for the amplified detection of a single-base mismatch in DNA using microgravimetric quartzcrystal-microbalance as transduction means (Figure 8) [81]. All methods involve the primary incorporation of a biotinylated base complementary to the mutation site in the analyzed double-stranded primer/DNA assembly. The double-stranded assembly is formed between 25 complementary bases of the probe DNA assembled on the Au-quartz crystal and the target DNA. One method of amplification includes the association of avidin- and biotin-labeled liposomes to the sensing interface. The second method of amplified detection of the base mismatch includes the association of an Au-nanoparticle-avidin conjugate to the sensing interface, and the secondary Au-nanoparticle-catalyzed deposition of gold on the particles. The third amplification route includes the binding of the avidin-alkaline phosphatase biocatalytic conjugate to the double-stranded surface followed by the oxidative hydrolysis of 5-bromo-4-chloro-3-indolyl phosphate to the insoluble product indigo derivative that precipitates on the transducer. Comparison of the three amplification routes reveals that the catalytic deposition of gold on the Au-nanoparticle/avidin conjugate is the most sensitive method, and the single-base mismatch in the analyzed DNA is detected with a sensitivity that corresponds to $3 \times 10^{-16} \mathrm{M}$.

A novel amplification route for DNA detection based on the deposition of gold on a $10 \mathrm{~nm}$ Au-colloid/avidin conjugate label acting as a "seeding" catalyst is described by Weizmann et al. (Figure 9) [66]. Microgravimetric quartz-crystal-microbalance measurements are employed to transduce the catalyzed deposition of gold on the piezoelectric crystals. Three different DNA detection schemes are described: 1) analysis of a 27-base nucleic acid fragment; 2) analysis of the entire M13f DNA (7229 bases); and 3) detection of a single-base mismatch in a DNA. Ultrasensitive detection of DNA is accomplished by the catalyzed deposition of gold, detection limit $\approx 1 \times$ $10^{-15} \mathrm{M}$.

A rapid and sensitive detection method for the early diagnosis of infectious dengue virus (DENV) urgently needs to be developed by Chen et al. [82]. In this study, a circulating-flow Quartz Crystal Microbalance (QCM) biosensing method combining oligonucleotide-functionalized gold nanoparticles (i.e. AuNP probes) used to detect DENV has been established. The sensitivity and specificity of the present DNA-QCM method with nanoparticle technology showed it to be comparable to the fluorescent real-time PCR methods. Moreover, the method described herein was shown to not require expensive equipment, was label-free and highly sensitive. Scodeller et al. reported a fully integrated core-shell nanoparticle system responsive to glucose [83]. The system is comprised of self-assembled glucose oxidase and an osmium molecular wire on core-shell Au nanoparticles. 

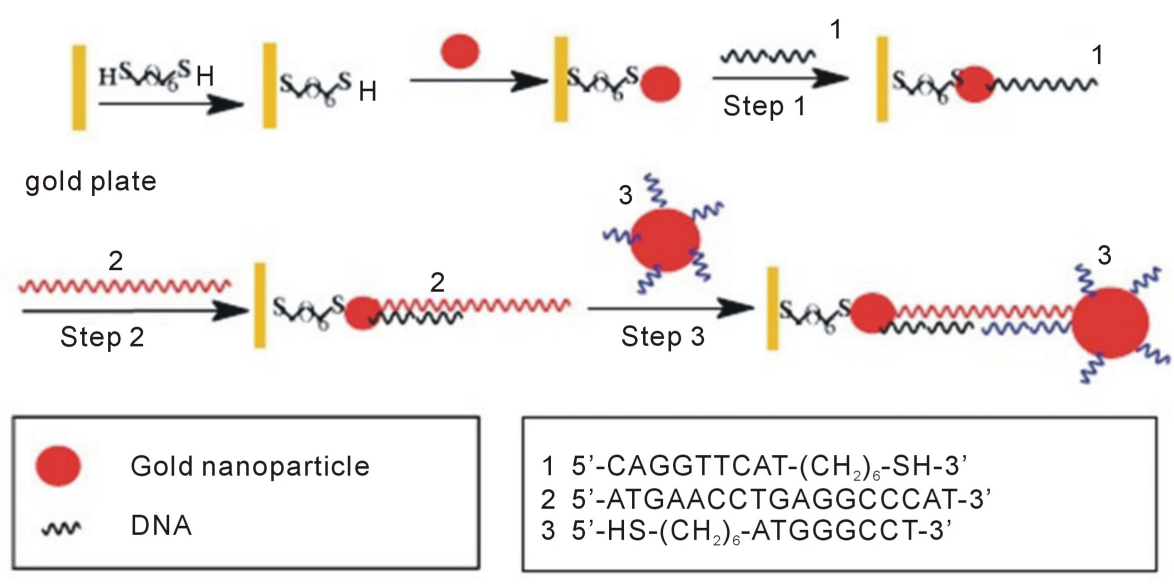

Figure 7. Schematic illustration of the sensing process of the amplifying system based on Au nanoparticle-covered QCM surface. Reproduced with permission from Ref. [63], Copyright 2004 Elsevier.

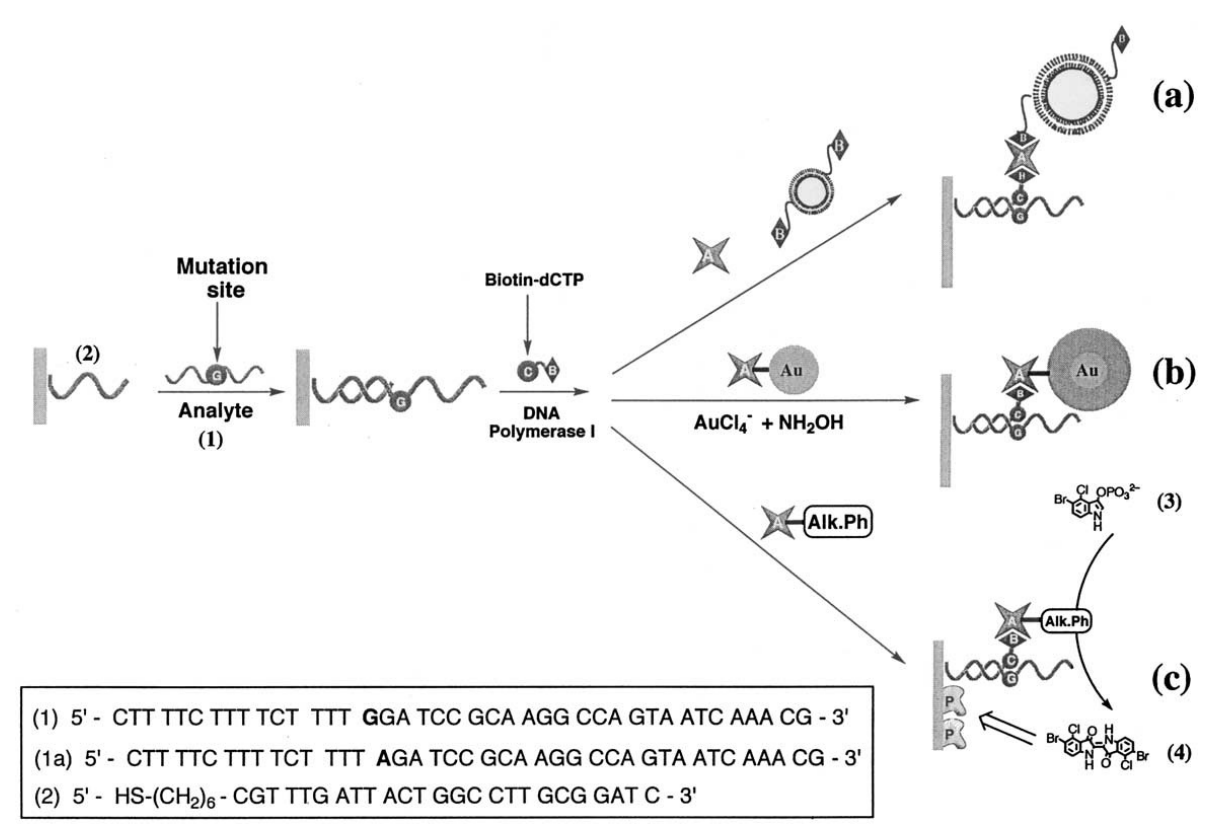

Figure 8. Amplified detection paths of a single-base mismatch in nucleic acids: (a) using avidin and biotin-labeled liposomes; (b) Using an avidin-Au-nanoparticle conjugate and the catalyzed deposition of gold; (c) Using an avidin-alkaline phosphatase bioconjugate and the biocatalyzed precipitation of the insoluble product 4 Reproduced with permission from Ref. [81], Copyright 2002 Elsevier.

In an interesting work Krozer et al., investigated a new and generic approach for integration of molecularly imprinted nanoparticles into sensing systems [84]. Nanoparticles can be easily immobilized on flat transducer surfaces through a supporting polymer film using spin-coating, and the thickness of the nanoparticle coating can be easily controlled by changing the nanoparticle/polymer ratio and the solid content of the nanoparticle suspension. Kong et al. was developed a molecularly imprinted Quartz Crystal Microbalance (QCM) sensor for ractopamine (RAC) detection by electrodepositing a poly-o-aminothiophenol membrane on an Au electrode surface modified by self-assembled Au nanoparticles (AuNPs) [85].

Recently a simple and sensitive sensor method for cancer biomarkers [prostate specific antigen (PSA) and PSA-alpha 1 antichymotrypsin (ACT) complex] analysis was developed, to be applied directly with human serum (75\%) by using antibody modified quartz crystal microbalance sensor and nanoparticles amplification sys- 


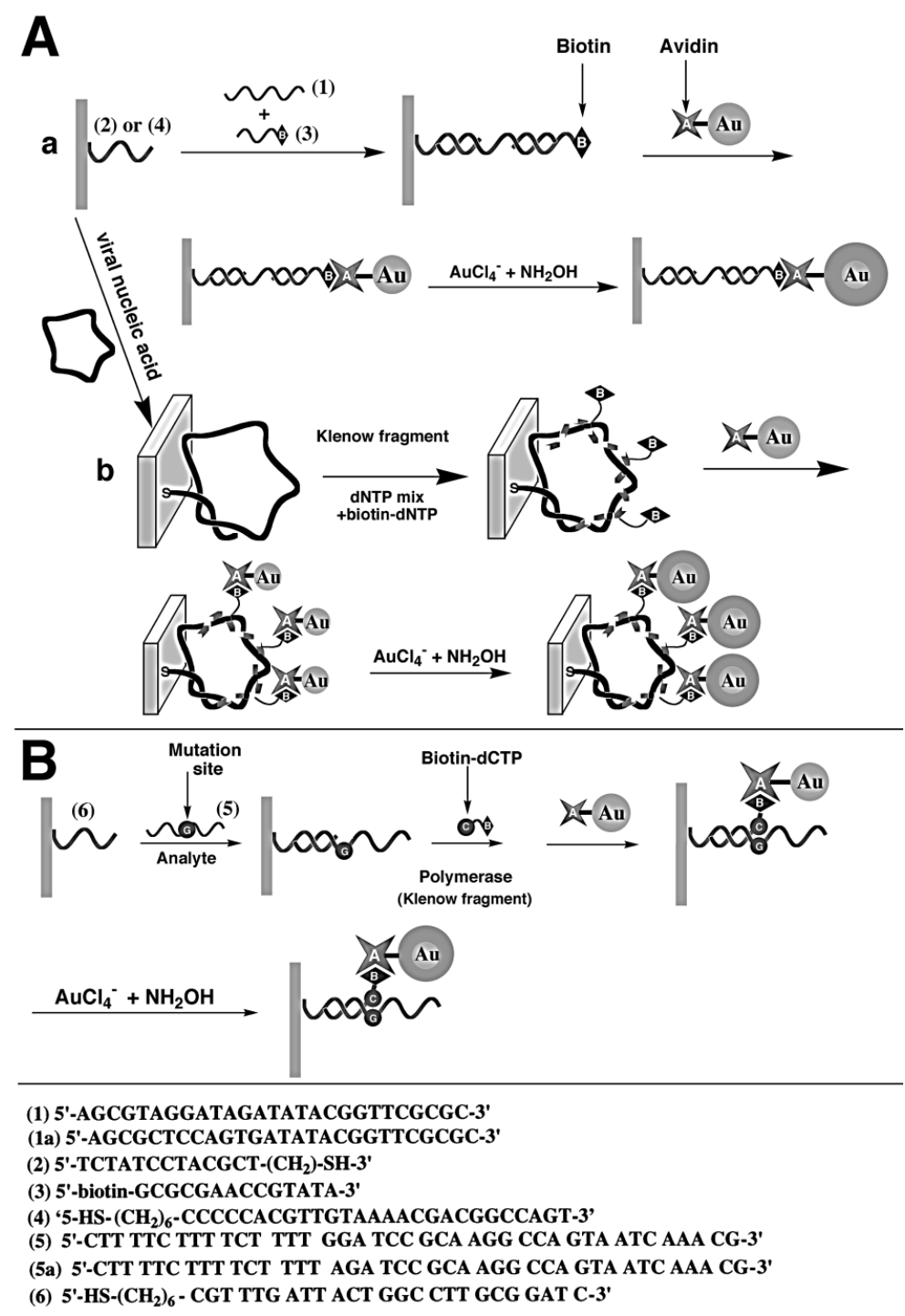

Figure 9. (A) Amplified detection of DNA by: (a) association of an Au-avidin conjugate and catalytic deposition of Au; (b) polymerase-induced replication of DNA followed by the electroless deposition of gold on an Au-avidin conjugate linked to the double-stranded assembly. (B) Amplified detection of a singlebase mismatch in DNA by the catalytic deposition of Au on an Au-avidin conjugate linked to the labeled double-stranded assembly. Reproduced with permission from Ref. [66], Copyright 2001 Royal Society of Chemistry.

tem [86]. A QCM sensor chip consisting of two sensing array enabling the measurement of an active and control binding events simultaneously on the sensor surface was used in this work. With the achieved detection limit in serum samples, the developed QCM assay show a promising technology for cancer biomarker analysis in patient samples.

Ma et al. reported a new amplification route for human lung carcinoma cell detection based on the detection of gold deposition on an Au-antibody conjugate label acting as a "seeding” catalyst [87]. Quartz crystal microbalance (QCM) was employed to measure the catalyzed deposition of gold on the piezoelectric crystals. The gold-coated quartz crystal was modified by polystyrene films, which provided a substrate for antibody immobilization by physical adsorption (Figure 10). The polystyrene films significantly improve the surface smoothness of the electrode. Compared to the conventional Enzymelinked Immunosorbent Assay (ELISA), the method described herein is a less time consuming procedure and gives comparable detection sensitivity of human lung carcinoma cells, $c a$. 100 cells $\mathrm{mL}^{-1}$. This will be of great significance in the diagnosis of this disease.

A highly sensitive quartz crystal microbalance with dissipation monitoring (QCM-D) biosensor for protein 

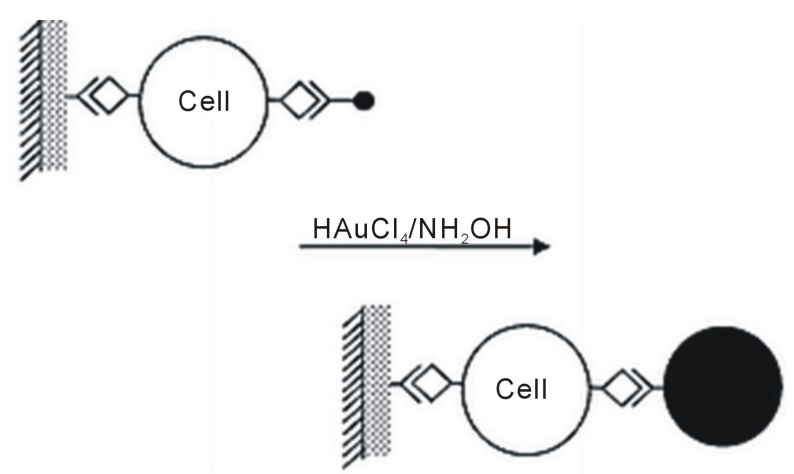

Figure 10. The gold-coated quartz crystal was modified by polystyrene filmsReproduced with permission from Ref. [87], Copyright 2002 Royal Society of Chemistry.

was developed using aptamer-functionalized gold nanoparticles (Apt-GNPs) for amplification [88]. Human $\alpha$-thrombin, an important physiological protease found in blood, was chosen as the target protein. Captured by immobilized aptamers, thrombin was determined on-line using Apt-GNPs to enhance both frequency and dissipation signals. The fabricated sandwich of aptamer/thrombin/Apt-GNPs on chip surface was confirmed by atomic force microscopy (AFM). Compared to direct assay, the detection limit for thrombin was down to 0.1 $\mathrm{nM}$, yielding about 2 orders of magnitude improvement in sensitivity. For the first time, the dual-signal enhancement of Apt-GNPs on QCM-D sensing was demonstrated, and such design could provide a promising detection strategy for proteins with two binding sites. Also an aptamer-based quartz crystal microbalance (QCM) biosensor was developed for the selective and sensitive detection of leukemia cells [89]. In this strategy, aminophenylboronic acid-modified gold nanoparticles (APBA-AuNPs) which could bind to cell membrane were used for the labeling of cells followed by silver enhancement, through which significant signal amplification was achieved.

In an interesting work Kaufman et al., described the adsorption characteristics of three proteins [bovine serum albumin (BSA), myoglobin (Mb), and cytochrome $c(\mathrm{CytC})$ ] onto self-assembled monolayers of mercaptoundecanoic acid (MUA) on both gold nanoparticles (AuNP) and gold surfaces (Au) [90]. The combination of quartz crystal microbalance measurements with dissipation (QCM-D) and $\mathrm{pH}$ titrations of the ú-potential provide information on layer structure, surface coverage, and potential. A new quartz crystal microbalance immunoassay method based on a novel transparent immunoaffinity reactor was developed for clinical immunoassay by Tang et al. [91]. To construct such an affinity reactor, resonators with a frequency of $10 \mathrm{MHz}$ were fabricated by affinity binding of functionalized gold nanoparticles (nanogold) to quartz crystal with immobilized specific ligand for the label-free analysis of the affinity reaction between a ligand and its receptor. [Recombinant human tumor markers, carcinoembryonic antigen (CEA) was chosen as a model ligand.]. Compared with the conventional enzyme-linked immunosorbent assay, the proposed immunoassay system was simple and rapid without multiple labeling and separation steps. Importantly, the proposed immunoassay system could be further developed for the immobilization of other antigens or biocompounds.

Su et al. fabricated novel low-humidity sensors by the in situ photopolymerization of polypyrrole/Ag/TiO nanoparticles (PPy/Ag/TiO $/ \mathrm{TP}_{2} \mathrm{NP}$ ) composite thin films on a quartz-crystal microbalance (QCM) [92]. The sensitivity increased with the doping amount of $\mathrm{TiO}_{2} \mathrm{NPs}$. Additionally, based on the dynamic analysis of adsorption, the association constants of water vapor molecules with PPy/Ag and PPy/Ag/50 wt\% $\mathrm{TiO}_{2} \mathrm{NPs}_{\mathrm{N}}$ composite thin films were estimated to be 81.6 and $227.9 \mathrm{M}^{-1}$, respectively, explaining the effect of adding $50 \mathrm{wt} \% \mathrm{TiO}_{2} \mathrm{NPs}_{\text {to }}$ PPy/Ag; the sensitivity to low humidity increased as the association constant increased. Also a sensitive method for ammonia gas analysis was developed with conducting polymer poly (3,4-ethylenedioxythiophene) (PEDOT) nanoparticles by reverse micelle method, which could be well dispersed in water or alcoholic solvent with ultrasonic treatment [93]. Compare to electrical conductivity of conventional PEDOT particles (ca. $0.5 \mathrm{~S} / \mathrm{cm}$ ), the as-prepared palletized nanoparticles have higher conductivity (ca. $10.2 \mathrm{~S} / \mathrm{cm}$ ) and the conductivity varies with the doped and de-doped states of PEDOT. As for sensing property, it has been found that QCM device coated with nanoparticles shows faster response and recovery to $20 \mathrm{ppm}$ ammonia gas (ca. $50 \mathrm{~s}$ ) than that of conventional PEDOT particles (Figure 11). The PEDOT nanoparticle covered device exhibits almost linear relation to 
lower $\mathrm{NH}_{3}$ gas concentration and shows a saturate tendency of gas sensitivity with the increase of gas concentration over $500 \mathrm{ppm}$.

Real-time and sensitive detection of Salmonella typhimurium using an automated quartz crystal microbalance (QCM) instrument with gold nanoparticles amplification was described by Salam et al. [94]. Also Guo et al. described a piezoelectric immunosensor for specific capture and enrichment of viable pathogens by quartz crystal microbalance sensor, followed by detection with antibody-functionalized gold nanoparticles [95]. The unique advantages of the system developed offer great potential in the microbial analysis of food samples in routine settings.

One of the applications of QCM technique is study nanoparticle self-assembly processes, nanocomposite materials and track nanoparticle interactions in the environment. Self-assembly is a process where similar particles spontaneously bind to one another to form new materials, coatings or films with a variety of desirable properties (Figure 12). These type of mass sensitive technique is highly useful to study monolayer formation, enzyme immobilization, selective sensing of small organic or large biomolecules. For example, recently Crooks and coworkers have shown that hyperbranch polymer monolayers and poly (amidoamine) dendrimer monolayers can interact with small organic molecules [97] [98]. Similarly Kepley and coworkers have used copper (II) ions bound on SAM to selectively and reversibly detected organophosphonate [99]. Host-guest interactions can be monitored by highly ordered cavitated monolayers as shown using calyx [4] resorcinarene [100]. These cavited monolayers have a high affinity towards perchloroethylene [100]. The QCM technology enables one to measure the kinetics of nanoparticle self-assembly processes; measure the resulting thickness, mass and structural properties of the self-assembled film; and compare the self-assembly process under different conditions such as temperature, solvent type or concentration, flow or static environment and particle type.

Modifying polymer films with nanoparticles to form nanocomposite materials has become a useful method to modulate the structural properties and other characteristics of thin films to have more desirable properties and better stability (Figure 13). The QCM-D technology can be used to study changes in film thickness and rigidity due to the additional of nanoparticles. Properties such as thickness, viscosity, storage and loss modulus of nanocomposite materials can be measured, in real time, by QCM. There is concern that nanoparticles stable in the environment could cause significant health issues. The QCM technology can also be used to track nanoparticle stability and interactions under environmental conditions with a variety of real-life surfaces such as glass, metals and natural organic matter (Figure 14). The technique can track the kinetics, extent and stability of nanoparticle deposition onto different surfaces and in different environmental conditions.

Chen et al. described the fabrication of gold nanoparticle surface thin films by taking advantage of the strong complexation interactions between transition metal ions and pyridine functional groups (Figure 15) [101]. The thickness (layers) of the particle thin films was readily controlled by the repetition of the alternate dipping cycles, as monitored by Quartz Crystal Microbalance (QCM).

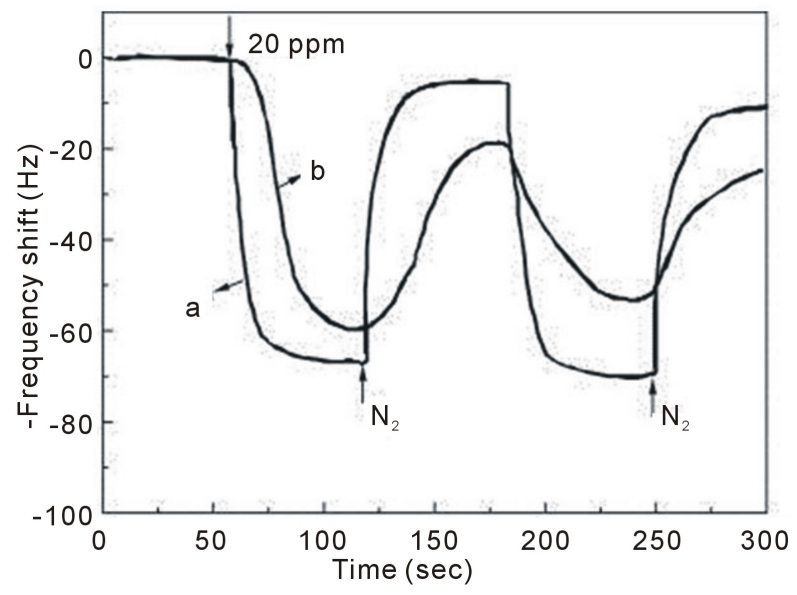

Figure 11. Typical response of PEDOT particles to $\mathrm{NH}_{3}$ gas (20 ppm) (a) nanoparticles and (b) conventional particles reproduced with permission from Ref. [93], Copyright 2007 Elsevier. 


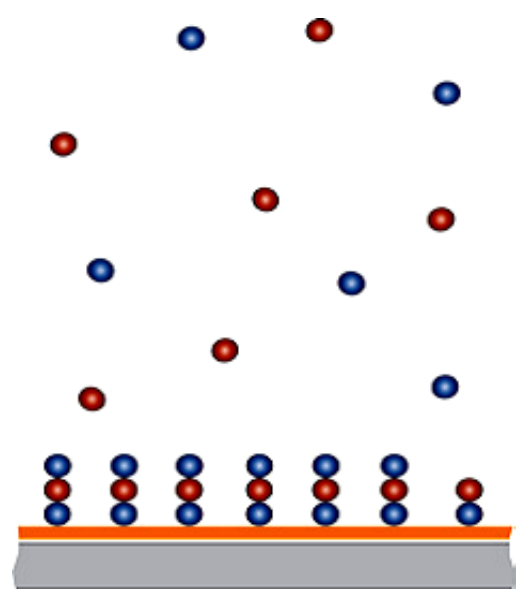

Figure 12. Self assembly processes [96].
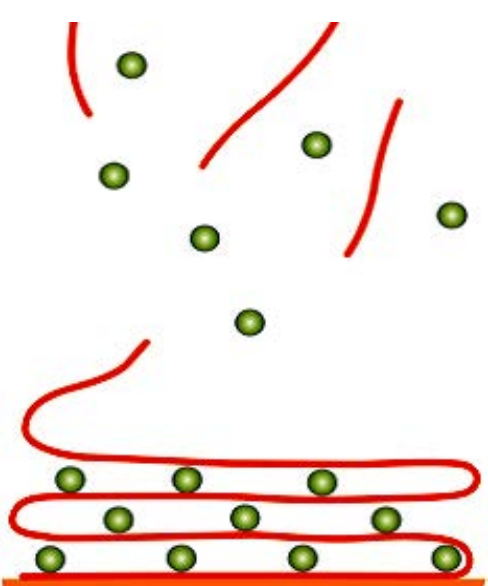

Figure 13. Nanocomposite materials analysis [96].

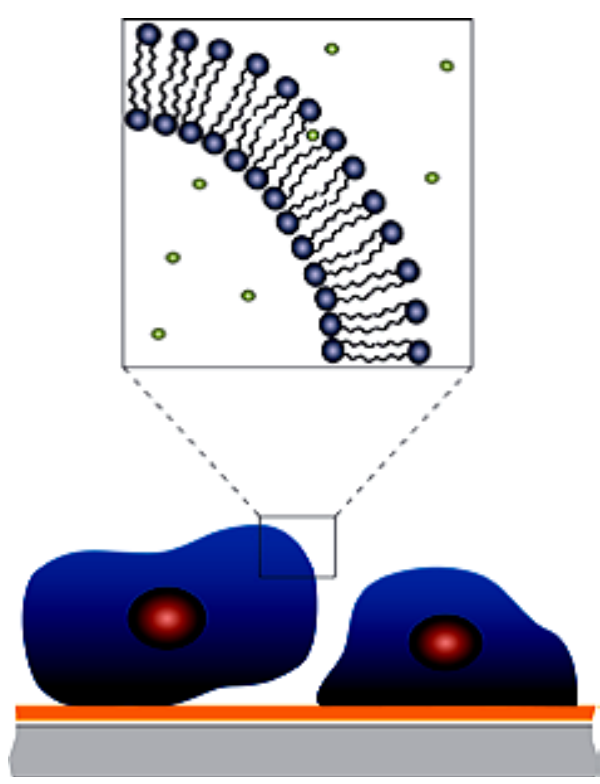

Figure 14. Nanoparticle interactions in the environment [96]. 


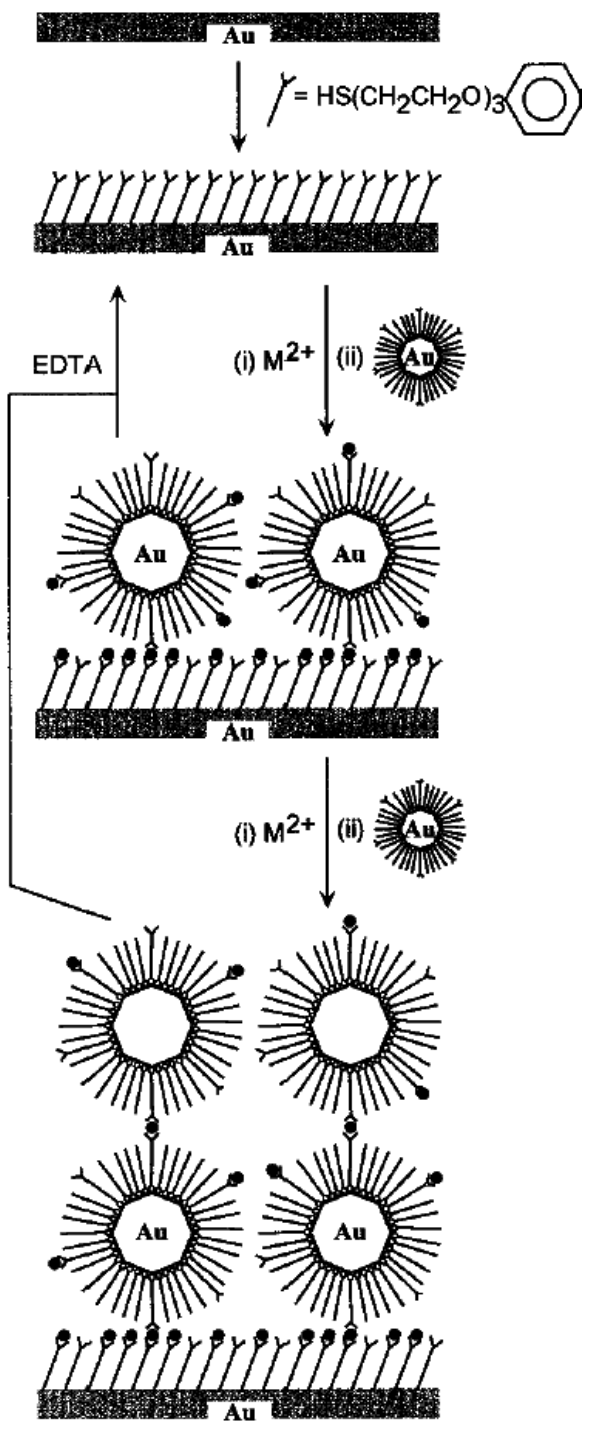

Figure 15. Procedure for nanoparticle assembling by the chelating interactions between divalent (transition) metal ions and pyridine moieties [101] reproduced with permission from Ref. [101], Copyright 2002 American Chemical Society.

Shen et al. investigated a means of producing Au nanoparticle network-type thin films that are derived by a one-step mixed-assembly cross-linking route, can avoid nonspecific interactions, and provide maximum binding to a specific target (Figure16) [102].

Liu and Hu showed interaction between myoglobin and hyaluronic acid in their layer-by-layer assembly by quartz crystal microbalance and cyclic voltammetry studies [103]. Quartz Crystal Microbalance (QCM) and CV were used to confirm the film growth and characterize the films. Also the deposition of silica nanoparticles on alumina coated surfaces in aqueous electrolytes was studied by optical reflectometry (OR) and a quartz crystal microbalance with dissipation (QCM-D) [104].

\section{Conclusion}

Quartz crystal microbalances have emerged in the last few years as versatile biosensors demonstrating remarkable achievements such as high sensitivity and label free detection. In the quartz crystal microbalance, the bioreaction generates a change in the mass, reordering the charges in the surface of the piezoelectric material and 


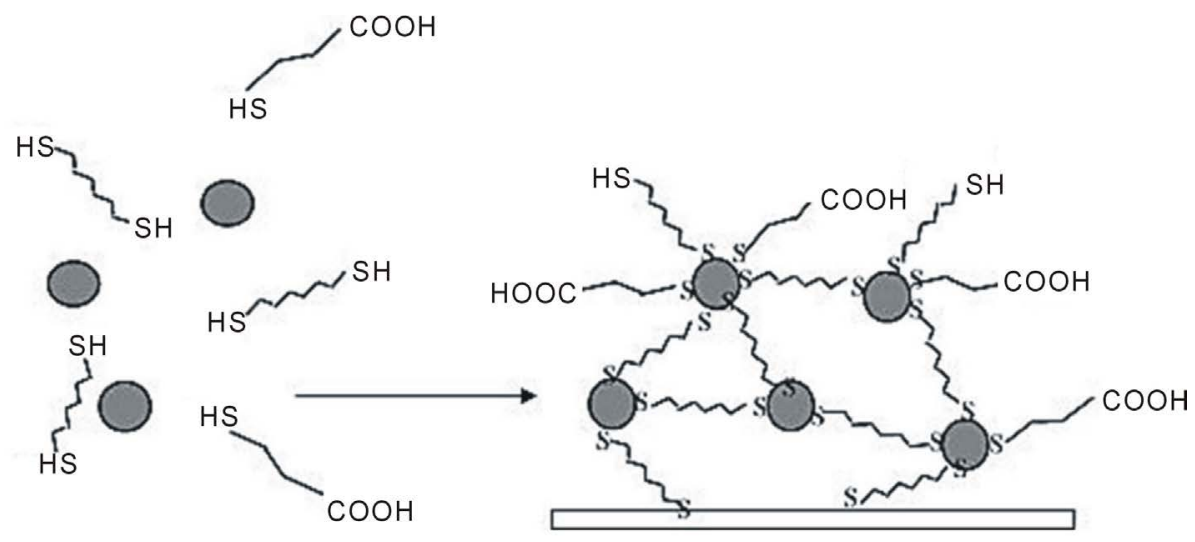

Figure 16. Schematic of the mixed-assembly cross-linking route for the preparation of Au nanoparticle network-type thin film. Reproduced with permission from Ref. [102], Copyright 2007 Elsevier.

giving rise to a change in the resonant frequency of the microbalance. Its detection range and sensitivity are not quite as good as some other label-free sensor technologies (e.g. surface plasmon resonance). The use of NP labels in sandwich assays can increase both the surface stress and the mass of the immune complex, allowing the increase in sensitivity of these electromechanical assays. This progress will require an increased understanding of both theoretical and experimental aspects of the relation among changes in frequency, energy dissipation, and NPs. These advancements will have a tremendous impact on the versatility and effectiveness of the QCM in future applications. In this review, application of nanoparticles in Quartz Crystal Microbalance biosensors has been extensively reviewed. The theoretical/experimental analysis, design and applications of quartz crystal microbalance biosensors combined with nanoparticles amplification have been discussed. These biosensors present as a detection option that can be effectively employed to specific pathogen related requirements. The prospects are low detection limit, less time consuming, economical, biocompatible, precise and accurate like features. New nanoparticles need to be explored for use in these biosensors. Therefore, QCM is a relatively new and promising research area worthy for further exploration.

\section{References}

[1] Agasti, S.S., Rana, S., Park, M.H., Kim, C.K., You, C.C. and Rotello, V.M. (2010) Nanoparticles for Detection and Diagnosis. Advanced Drug Delivery Reviews, 62, 316-328. http://dx.doi.org/10.1016/j.addr.2009.11.004

[2] Durner, J. (2009) Clinical Chemistry: Challenges for Analytical Chemistry and the Nanosciences from Medicine. Angewandte Chemie International Edition, 496, 1026-1051. http://dx.doi.org/10.1002/anie.200903363

[3] Palchetti, I. and Mascini, M. (2008) Nucleic Acid Biosensors for Environmental Pollution Monitoring. Analyst, 133, 846-854. http://dx.doi.org/10.1039/b802920m

[4] Arbab Zavar, M.H., Heydari, S., Rounaghi, Gh., Eshghi, H. and Azizi-Toupkanloo, H. (2012) Electrochemical Behavior of Para-Nitroaniline at a New Synthetic Crownether-Silver Nanoparticle Modified Carbon Paste Electrode. Analytical Methods, 4, 953-958.

[5] Rounaghi, G.H., Mohamadzadehkakhki, R. and Azizi-Toupkanloo, H. (2012) Voltammetric Determination of 4-Nitrophenol Using a Modified Carbon Paste Electrode Based on a New Synthetic Crown Ether/Silver Nanoparticles. Material Science and Engineering C, 32, 172-177.

[6] Cady, W.G. (1946) Piezoelectricity. McGraw-Hill, New York and London.

[7] Curie, J. and Curie, P. (1880) Mull Historical Society, Paris, 1880, 90.

[8] Lippman, G. (1881) Principe de conservation de lelectricite. Annales de Chimie et de Physique, 24, 145-178.

[9] Dwyer, M.A. and Hellinga, H.W. (2004) Periplasmic Binding Proteins: A Versatile Superfamily for Protein Engineering. Current Opinion in Structural Biology, 14, 495-504. http://dx.doi.org/10.1016/j.sbi.2004.07.004

[10] Rabe, J., Buttgenbach, S., Schroder, J. and Hauptmann, P. (2003) Monolithic Miniaturized Quartz Microbalance Array and Its Application to Chemical Sensor Systems for Liquids. IEEE Sensors Journal, 3, 361-368. http://dx.doi.org/10.1109/JSEN.2003.815783

[11] Sauerbrey, G. (1959) Verwendung von Schwingquarzenzur Wagungdunner Schichten und zur Mikrowagung. Zeit- 
schrift für Physik, 155, 206-222. http://dx.doi.org/10.1007/BF01337937

[12] Kanazawa, K. and Gordon Ii, J.G. (1985) The Oscillation Frequency of a Quartz Resonator in Contact with Liquid. Analytica Chimica Acta, 175, 99-105. http://dx.doi.org/10.1016/S0003-2670(00)82721-X

[13] Ward, M.D. and Delawski, E.J. (1991) Radial Mass Sensitivity of the Quartz Crystal Microbalance in Liquid Media. Analytical Chemistry, 63, 886-890. http://dx.doi.org/10.1021/ac00009a009

[14] Lin, Z., Yip, C.M., Scott Joseph, I. and Ward, M.D. (1993) Operation of an Ultrasensitive 30 MHz Quartz Crystal Microbalance in Liquids. Analytical Chemistry, 65, 1546-1551. http://dx.doi.org/10.1021/ac00059a011

[15] Rodahl, M. and Kasemo, B. (1996) A Simple Setup to Simultaneously Measure Liquid Deposits on a QCM Electrode. Sensors and Actuators B, 37, 111-116.

[16] Muramatsu, H., Tamiya, E. and Karube, I. (1988) Computation of Equivalent Circuit Parameters of Quartz Crystals in Contact with Liquid and Study of Liquid Properties. Analytical Chemistry, 60, 2142-2146. http://dx.doi.org/10.1021/ac00170a032

[17] Rodahl, M., Hook, F., Fredriksson, C., Keller, C.A., Krozer, A., Brzezinski, P., Voinova, M. and Kasemo, B. (1997) Simultaneous Frequency and Dissipation Factor QCM Measurements of Biomolecular Adsorption and Cell Adhesion. Faraday Discussions, 107, 229-246. http://dx.doi.org/10.1039/a703137h

[18] Penza, M., Cassano, G., Aversa, P., Antolini, F., Cusano, A., Cutolo, A., Giordano, M. and Nicolais, L. (2004) Alcohol Detection Using Carbon Nanotubes Acoustic and Optical Sensors. Applied Physics Letters, 85, 2379-2381. http://dx.doi.org/10.1063/1.1784872

[19] Matsuguchi, M. and Uno, T. (2006) Molecular Imprinting Strategy for Solvent Molecules and Its Application for QCM-Based VOC Vapor Sensing. Sensors and Actuators B, 113, 94-99. http://dx.doi.org/10.1016/j.snb.2005.02.028

[20] Brousseau III, L.C., Aurentz, D.J., Benesi, A.J. and Mallouk, T.E. (1997) Molecular Design of Intercalation-Based Sensors. 2. Sensing of Carbon Dioxide in Functionalized Thin Films of Copper Octanediylbis(phosphonate). Analytical Chemistry, 69, 679-687.

[21] Ding, B., Kim, J., Miyazaki, Y. and Shiratori, S. (2004) Electrospun Nanofibrous Membranes Coated Quartz as Gas Sensor for NH3 Detection. Sensors and Actuators B, 101, 373-380. http://dx.doi.org/10.1016/j.snb.2004.04.008

[22] Wang, X.H., Zhang, J., Zhu, Z.Q. and Zhu, J.Z. (2007) Humidity Sensing Properties of Pd ${ }^{2+}$-Doped ZnO Nanotetrapods. Applied Surface Science, 253, 3168-3173.

[23] King, W.H. (1964) Piezoelectric Sorption Detector. Analytical Chemistry, 36, 1735-1739. http://dx.doi.org/10.1021/ac60215a012

[24] Bottom, V.E. (1982) Introduction to Quartz Crystal Unit Design. Van Nostrand Reinhold, New York.

[25] Bruckenstein, S., Fensore, A., Li, Z.F. and Hillman, A.R. (1994) Dual Quartz Crystal Microbalance Compensation Using a Submerged Reference Crystal. Effect of Surface Roughness and Liquid Properties. Journal of Electroanalytical Chemistry, 370, 189-195. http://dx.doi.org/10.1016/0022-0728(93)03205-4

[26] Bruckenstein, S., Michalskl, M., Fensore, A., Zhufen, L.I. and Hillman, A.R. (1994) Dual Quartz Crystal Oscillator Circuit. Minimizing Effects Due to Liquid Viscosity, Density, and Temperature. Analytical Chemistry, 66, 1847-1852. http://dx.doi.org/10.1021/ac00083a012

[27] Dunham, G.C., Benson, N.H., Petelenz, D. and Janata, J. (1995) Dual Quartz Crystal Microbalance. Analytical Chemistry, 67, 267-272. http://dx.doi.org/10.1021/ac00098a005

[28] Uno, T. (1996) Frequency Control Symposium, 50th, Proceedings of the 1996 IEEE International, 526-531.

[29] Cooper, M.A. and Singleton, V.T. (2007) A survey of the 2001 to 2005 Quartz Crystal Microbalance Biosensor Literature: Applications of Acoustic Physics to the Analysis of Biomolecular Interactions. Journal of Molecular Recognition, 20, 154-184. http://dx.doi.org/10.1002/jmr.826

[30] ArbabZavar, M.H., Heydari, S., Rounaghi, G. and Ashraf, N. (2011) Graphite Disk Lanthanum(III)-Selective Electrode Based on Benzo-15-Crown-5. Journal of the Electrochemical Society, 158, F142-F146. http://dx.doi.org/10.1149/1.3587109

[31] Rounaghi, G.H. and Adzadeh Kakhki, R.M. (2011) Highly Selective and Sensitive Coated-Wire Yttrium (III) Cation Selective Electrode Based on Kryptofix-22DD. Journal of the Electrochemical Society, 158, F121-F125. http://dx.doi.org/10.1149/1.3582316

[32] Arbab Zavar, M.H., Heydari, S. and Rounaghi, G. (2013) Electrochemical Determination of Salicylic Acid at a New Biosensor Based on Polypyrrole-Banana Tissue Composite. Arabian Journal for Science and Engineering, 38, 29-36. http://dx.doi.org/10.1007/s13369-012-0411-2

[33] Zadeh kakhki, R.M., Ronagi, G.H. and Sadeghian, H. (2011) A New Cerium (III) Ion Selective Electrode Based on 2,9-Dihydroxy-1,10-Diphenoxy-4,7-Dithia Decane, a Novel Synthetic Ligand. Electrochimica Acta, 56, 9756-9761.

[34] Arbab Zavar, M.H., Heydari, S., Rounaghi, G.H., Eshghi, H. and Sadeghian, H. (2012) Nano-Level Monitoring of Yt- 
trium by a Novel PVC-Membrane Sensor Based on 2,9-dihydroxy-1,10-diphenoxy-4,7-dithiadecane. Croatica Chemica Acta, 85, 131-137. http://dx.doi.org/10.5562/cca1937

[35] Zadeh Kakhki, R.M. and Rounaghi, G. (2011) Selective Uranyl Cation Detection by Polymeric Ion Selective Electrode Based on Benzo-15-Crown-5. Materials Science \& Engineering: C, 31, 1637-1642. http://dx.doi.org/10.1016/j.msec.2011.07.007

[36] Carmon, K. (2004) Development of a QCM Biosensor Using Receptor Proteins to Detect the Binding of Small Ligands. Thesis. Clarkson University, Potsdam.

[37] Marx, K.A. (2003) Quartz Crystal Microbalance: A Useful Tool for Studying Thin Polymer Films and Complex Biomolecular Systems at the Solution-Surface Interface. Biomacromolecules, 4, 1099-1120. http://dx.doi.org/10.1021/bm020116i

[38] Thompson, M. and Hayward, G.L. (1997) Mass Response of the Thickness-Shear Mode Acoustic Wave Sensor in Liquids as a Central Misleading Dogma. IEEE International Frequency Control Symposium, Orlando, 28-30 May 1997, 114-119.

[39] Janshoff, A., Galla, H.J. and Steinem, C. (2000) Piezoelectric Mass-Sensing Devices as Biosensors. An Alternative to Optical Biosensors. Angewandte Chemie International Edition, 39, 4004-4032.

http://dx.doi.org/10.1002/1521-3773(20001117)39:22<4004::AID-ANIE4004>3.0.CO;2-2

[40] Cooper, M.A. (2003) Biosensor Profiling of Molecular Interactions in Pharmacology. Current Opinion in Pharmacology, 3, 557-562. http://dx.doi.org/10.1016/j.coph.2003.05.003

[41] Cooper, M.A. (2006) Resonant Acoustic Profiling (RAPTM) and Rupture Event Scanning (REVSTM). In: Steinem, C. and Janshoff, A., Eds., Piezoelectric Sensors, Vol. 5, Springer-Verlag, Berlin, Heidelberg, 449-481.

[42] Cote, G.L., Lec, R.M. and Pishko, M.V. (2003) Emerging Biomedical Sensing Technologies and Their Applications. IEEE Sensors Journal, 3, 251-266. http://dx.doi.org/10.1109/JSEN.2003.814656

[43] Hook, F. and Kasemo, B. (2006) In the QCM-D Technique. In: Steinem, C. and Janshoff, A., Eds., Piezoelectric Sensors, Vol. 5, Springer-Verlag, Berlin, Heidelberg, 425-449.

[44] Steinem, C. and Janshoff, A. (2006) In Piezoelectric Sensors. Springer-Verlag, Berlin, Heidelberg.

[45] Braunhut, S., McIntosh, D., Vorotnikova, E., Zhou, T. and Marx, K.A. (2005) Detection of Apoptosis and Drug Resistance of Human Breast Cancer Cells to Taxane Treatments Using Quartz Crystal Microbalance Biosensor Technology. ASSAY and Drug Development Technologies, 3, 77-88. http://dx.doi.org/10.1089/adt.2005.3.77

[46] Kim, Y.S., Niazi, J.H. and Gu, M.B. (2009) Specific Detection of Oxytetracycline Using DNA Aptamer-Immobilized Interdigitated Array Electrode Chip. Analytica Chimica Acta, 634, 250-254. http://dx.doi.org/10.1016/j.aca.2008.12.025

[47] Proske, D., Blank, M., Buhmann, R. and Resch, A. (2005) Aptamers-Basic Research, Drug Development, and Clinical Applications. Applied Microbiology and Biotechnology, 69, 367-374. http://dx.doi.org/10.1007/s00253-005-0193-5

[48] Xie, S. and Walton, S.P. (2009) Application and Analysis of Structure-Switching Aptamers for Small Molecule Quantification. Analytica Chimica Acta, 638, 213-219. http://dx.doi.org/10.1016/j.aca.2009.02.018

[49] Fang, L., Lu, Z., Wei, H. and Wang, E. (2008) A Electrochemiluminescence Aptasensor for Detection of Thrombin Incorporating the Capture Aptamer Labeled with Gold Nanoparticles Immobilized onto the Thio-Silanized ITO Electrode. Analytica Chimica Acta, 628, 80-86. http://dx.doi.org/10.1016/j.aca.2008.08.041

[50] Farokhzad, O.C., Jon, S., Khademhosseini, A., Tran, T.N., Lavan, D.A. and Langer, R. (2004) Nanoparticle-Aptamer Bioconjugates: A New Approach for Targeting Prostate Cancer Cells. Cancer Research, 64, 7668-7672. http://dx.doi.org/10.1158/0008-5472.CAN-04-2550

[51] Yao, C.Y., Zhu, T.Y., Qi, Y.Z., Zhao, Y.H., Xia, H. and Fu, W.L. (2010) Development of a Quartz Crystal Microbalance Biosensor with Aptamers as Bio-Recognition Element. Sensors, 10, 5859-5871. http://dx.doi.org/10.3390/s100605859

[52] Wu, V.C.H., Chen, S.H. and Lin, C.S. (2007) Real-Time Detection of Escherichia coli O157:H7 Sequences Using a Circulating-Flow System of Quartz Crystal Microbalance. Biosensors and Bioelectronics, 22, 2967-2975. http://dx.doi.org/10.1016/j.bios.2006.12.016

[53] Janeway Jr., C.A., Walport, M.J. and Travers, P. (2005) Immunobiology: The Immune System in Health and Disease. 6th Edition, Taylor \& Francis Group, New York.

[54] Ahirwal, G.K. and Mitra, C.K. (2010) Gold Nanoparticles Based Sandwich Electrochemical Immunosensor. Biosensors and Bioelectronics, 25, 2016-2020. http://dx.doi.org/10.1016/j.bios.2010.01.029

[55] Noble, J., Thobhani, S., Attree, S., Boyd, R., Kumarswami, N., Szymanski, M. and Porter, A. (2010) Bioconjugation and Characterisation of Gold Colloid-Labelled Proteins. Journal of Immunological Methods, 356, 60-69. http://dx.doi.org/10.1016/j.jim.2010.02.007 
[56] Fritz, J. (2008) Cantilever Biosensors. Analyst, 133, 855-863. http://dx.doi.org/10.1039/b718174d

[57] Wu, G.H., Datar, R.H., Hansen, K.M., Thundat, T., Cote, R.J. and Majumdar, A. (2001) Bioassay of Prostate-Specific Antigen (PSA) Using Microcantilevers. Nature Biotechnology, 19, 856-860. http://dx.doi.org/10.1038/nbt0901-856

[58] Milburn, C., Zhou, J., Bravo, O., Kumar, C. and Soboyejo, W.O. (2005) Sensing Interactions between Vimentin Antibodies and Antigens for Early Cancer Detection. Journal of Biomedical Nanotechnology, 1, 30-38. http://dx.doi.org/10.1166/jbn.2005.014

[59] Chu, X., Zhao, Z.L., Shen, G.L. and Yu, R.Q. (2006) Quartz Crystal Microbalance Immunoassay with Dendritic Amplification Using Colloidal Gold Immunocomplex. Sensors and Actuators B, 114, 696-704.

[60] Jin, X., Jin, X., Chen, L., Jiang, J., Shen, G. and Yu, R. (2009) Piezoelectric Immunosensor with Gold Nanoparticles Enhanced Competitive Immunoreaction Technique for Quantification of Aflatoxin B1. Biosensors \& Bioelectronics, 24, 2580-2585. http://dx.doi.org/10.1016/j.bios.2009.01.014

[61] Ward, M.D. and Ebersole, R.C. (1996) Piezoelectric Specific Binding Assay with Mass Amplified Reagents. US Patent No. 5501986.

[62] Su, X.D., Chew, F.T. and Li, S.F.Y. (2000) Design and Application of Piezoelectric Quartz Crystal-Based Immunoassay. Analytical Sciences, 16, 107-114. http://dx.doi.org/10.2116/analsci.16.107

[63] Liu, T., Tang, J. and Jiang, L. (2004) The Enhancement Effect of Gold Nanoparticles as a Surface Modifier on DNA Sensor Sensitivity. Biochemical and Biophysical Research Communications, 313, 3-7. http://dx.doi.org/10.1016/j.bbrc.2003.11.098

[64] Chu, P.T., Lin, C.S., Chen, W.J., Chen, C.F. and Wen, H.W. (2012) Detection of Gliadin in Foods Using a Quartz Crystal Microbalance Biosensor that Incorporates Gold Nanoparticles. Journal of Agricultural and Food Chemistry, 60, 6483-6492. http://dx.doi.org/10.1021/jf2047866

[65] Kaewphinit, T., Santiwatanakul, S. and Chansiri, K. (2012) Gold Nanoparticle Amplification Combined with Quartz Crystal Microbalance DNA Based Biosensor for Detection of Mycobacterium Tuberculosis. Sensors \& Transducers Journal, 146, 156-163.

[66] Weizmann, Y., Patolsky, F. and Willner, I. (2001) Amplified Detection of DNA and Analysis of Single-Base Mismatches by the Catalyzed Deposition of Gold on Au-Nanoparticles. Analyst, 126, 1502-1504. http://dx.doi.org/10.1039/b106613g

[67] Zhao, H.Q., Lin, L., Tang, J., Duan, M.X. and Jiang, L. (2001) Enhancement of the Immobilization and Discrimination of DNA Probe on a Biosensor Using Gold Nanoparticles. Chinese Science Bulletin, 46, 1074-1077. http://dx.doi.org/10.1007/BF02900680

[68] Willner, I., Patolsky, F., Weimann, Y. and Willner, B. (2002) Amplified Detection of Single-Base Mismatches in DNA Using Microgravimetric Quartz-Crystal-Microbalance Transduction. Talanta, 56, 847-856. http://dx.doi.org/10.1016/S0039-9140(01)00658-0

[69] Liu, T., Tang, J. and Jiang, L. (2002) Sensitivity Enhancement of DNA Sensors by Nanogold Surface Modification. Biochemical and Biophysical Research Communications, 295, 14-16. http://dx.doi.org/10.1016/S0006-291X(02)00628-9

[70] Fritzsche, W. and Taton, T.A. (2003) Metal Nanoparticles as Labels for Heterogeneous, Chip-Based DNA Detection. Nanotechnology, 14, R63-R73. http://dx.doi.org/10.1088/0957-4484/14/12/R01

[71] Liu, T., Tang, J., Han, M.M. and Jiang, L. (2003) Surface Modification of Nanogold Particles in DNA Detection with Quartz Crystal Microbalance. Chinese Science Bulletin, 48, 873-875. http://dx.doi.org/10.1007/BF03325667

[72] Ha, T.H., Kim, S., Lim, G. and Kim, K. (2004) Influence of Liquid Medium and Surface Morphology on the Response of QCM during Immobilization and Hybridization of Short Oligonucleotides. Biosensors and Bioelectronics, 20, 378-389. http://dx.doi.org/10.1016/j.bios.2004.02.027

[73] He, F.J. and Liu, S.Q. (2004) Detection of P. Aeruginosa Using Nano-Structured Electrode-Separated Piezoelectric DNA Biosensor. Talanta, 62, 271-277. http://dx.doi.org/10.1016/j.talanta.2003.07.007

[74] Liu, T., Tang, J., Zhao, H.Q., Deng, Y.P. and Jiang, L. (2002) Particle Size Effect of the DNA Sensor Amplified with Gold Nanoparticles. Langmuir, 18, 5624-5626. http://dx.doi.org/10.1021/la015765e

[75] Liu, S.F., Li, J.R. and Jiang, L. (2005) Surface Modification of Platinum Quartz Crystal Microbalance by Controlled Electroless Deposition of Gold Nanoparticles and Its Enhancing Effect on the HS-DNA Immobilization. Colloids and Surfaces A, 257-258, 57-62. http://dx.doi.org/10.1016/j.colsurfa.2004.10.059

[76] Zhang, R.Y., Pang, D.W., Zhang, Z.L., Yan, J.W., Yao, J.L., Tian, Z.Q., Mao, B.W. and Sun, S.G. (2002) Investigation of Ordered ds-DNA Monolayers on Gold Electrodes. Journal of Physical Chemistry B, 106, 11233-11239. http://dx.doi.org/10.1021/jp025817o

[77] Mo, Z.H., Wang, H.L., Liang, Y.L., Liu, F.W. and Xue, Y.X. (2005) Highly Reproducible Hybridization Assay of Zep- 
tomole DNA Based on Adsorption of Nanoparticle-Bioconjugate. Analyst, 130, 1589-1594. http://dx.doi.org/10.1039/b500949a

[78] Ma, Z.F., Li, J.R., Jiang, L., Yang, M.S. and Sui, S.F. (2002) High Sensitive DNA Detection Amplified by Enlarging Au-Nanoparticles in Situ. Chemistry Letters, 31, 328-329. http://dx.doi.org/10.1246/cl.2002.328

[79] Mao, X., Yang, L., Su, X.L. and Li, Y.B. (2006) A Nanoparticle Amplification Based Quartz Crystal Microbalance DNA Sensor for Detection of Escherichia coli O157:H7. Biosensors and Bioelectronics, 21, 1178-1185. http://dx.doi.org/10.1016/j.bios.2005.04.021

[80] Hao, R.Z., Song, H.B., Zuo, G.M., Yang, R.F., Wei, H.P., Wang, D.B., Cui, Z.Q., Zhang, Z., Cheng, Z.X. and Zhang, X.E. (2011) DNA Probe Functionalized QCM Biosensor Based on Gold Nanoparticle Amplification for Bacillus anthracis Detection. Biosensors and Bioelectronics, 26, 3398-3404. http://dx.doi.org/10.1016/j.bios.2011.01.010

[81] Willner, I., Patolsky, F., Weizmann, Y. and Willner, B. (2002) Amplified Detection of Single-Base Mismatches in DNA Using Microgravimetric Quartz-Crystal-Microbalance Transduction. Talanta, 56, 847-856. http://dx.doi.org/10.1016/S0039-9140(01)00658-0

[82] Chen, S.H., Chuang, Y.C., Lu, Y.C., Lin, H.C., Yang, Y.L. and Lin, C.S. (2009) A Method of Layer-by-Layer Gold Nanoparticle Hybridization in a Quartz Crystal Microbalance DNA Sensing System Used to Detect Dengue Virus. Nanotechnology, 20, Article ID: 215501. http://dx.doi.org/10.1088/0957-4484/20/21/215501

[83] Scodeller, P., Flexer, V., Szamocki, R., Calvo, E.J., Tognalli, N., Troiani, H. and Fainstein, A. (2008) Wired-Enzyme Core-Shell Au Nanoparticle Biosensor. Journal of the American Chemical Society, 130, 12690-12697. http://dx.doi.org/10.1021/ja802318f

[84] Reimhult, K., Yoshimatsu, K., Risveden, K., Chen, S., Ye, L. and Krozer, A. (2008) Characterization of QCM Sensor Surfaces Coated with Molecularly Imprinted Nanoparticles. Biosensors and Bioelectronics, 23, 1908-1914. http://dx.doi.org/10.1016/j.bios.2008.02.011

[85] Kong, L.J., Pan, M.F., Fang, G.Z., He, X.L., Yang, Y.K., Dai, J. and Wang, S. (2014) Molecularly Imprinted Quartz Crystal Microbalance Sensor Based on Poly(o-Aminothiophenol) Membrane and Au Nanoparticles for Ractopamine Determination. Biosensors and Bioelectronics, 51, 286-292. http://dx.doi.org/10.1016/j.bios.2013.07.043

[86] Uludag, Y. and Tothill, I.E. (2010) Development of a Sensitive Detection Method of Cancer Biomarkers in Human Serum (75\%) Using a Quartz Crystal Microbalance Sensor and Nanoparticles Amplification System. Talanta, 82, 277282. http://dx.doi.org/10.1016/j.talanta.2010.04.034

[87] Ma, Z.F., Wu, J.L., Zhou, T.H., Chen, Z.H., Dong, Y., Tang, J.T. and Sui, S.F. (2002) Detection of Human Lung Carcinoma Cell Using Quartz Crystal Microbalance Amplified by Enlarging Au Nanoparticles in Vitro. New Journal of Chemistry, 26, 1795-1798. http://dx.doi.org/10.1039/b206248h

[88] Chen, Q., Tang, W., Wang, D., Wu, X., Li, N. and Liu, F. (2010) Amplified QCM-D Biosensor for Protein Based on Aptamer-Functionalized Gold Nanoparticles. Biosensors and Bioelectronics, 26, 575-579. http://dx.doi.org/10.1016/j.bios.2010.07.034

[89] Shan, W.Q., Pan, Y.L., Fang, H.T., Guo, M.L., Nie, Z., Huang, Y. and Yao, S.Z. (2014) An Aptamer-Based Quartz Crystal Microbalance Biosensor for Sensitive and Selective Detection of Leukemia Cells Using Silver-Enhanced Gold Nanoparticle Label. Talanta, 126, 130-135. http://dx.doi.org/10.1016/j.talanta.2014.03.056

[90] Kaufman, E.D., Belyea, J., Johnson, M.C., Nicholson, Z.M., Ricks, J.L., Pavak, K., Shah, P.K., Bayless, M., Pettersson, T., Feldoto, Z., Blomberg, E., Claesson, P. and Franzen, S. (2007) Probing Protein Adsorption onto Mercaptoundecanoic Acid Stabilized Gold Nanoparticles and Surfaces by Quartz Crystal Microbalance and Potential Measurements. Langmuir, 23, 6053-6062. http://dx.doi.org/10.1021/la063725a

[91] Tang, D.Q., Zhang, D.J., Tang, D.Y. and Ai, H. (2006) Amplification of the Antigen-Antibody Interaction from Quartz Crystal Microbalance Immunosensors via Back-Filling Immobilization of Nanogold on Biorecognition Surface. Journal of Immunological Methods, 316, 144-152. http://dx.doi.org/10.1016/j.jim.2006.08.012

[92] Su, P.G. and Chang, Y.P. (2008) Low-Humidity Sensor Based on a Quartz-Crystal Microbalance Coated with Polypyrrole/Ag/ $\mathrm{TiO}_{2}$ Nanoparticles Composite Thin Films. Sensors and Actuators B, 129, 915-920.

http://dx.doi.org/10.1016/j.snb.2007.10.006

http://www.biolinscientific.com/q-sense/?file/qcm-d-and-nanoparticles-application-overview.pdf

[93] Yang, Y.J., Jiang, Y.D., Xu, J.H. and Yu, J.S. (2007) Conducting Polymeric Nanoparticles Synthesized in Reverse Micelles and Their Gas Sensitivity Based on Quartz Crystal Microbalance. Polymer, 48, 4459-4465. http://dx.doi.org/10.1016/j.polymer.2007.06.005

[94] Salam, F., Uludag, Y. and Tothill, I.E. (2013) Real-Time and Sensitive Detection of Salmonella Typhimurium Using an Automated Quartz Crystal Microbalance (QCM) Instrument with Nanoparticles Amplification. Talanta, 115, 761767. http://dx.doi.org/10.1016/j.talanta.2013.06.034

[95] Guo, X., Lin, C.S., Chen, S.H., Ye, R. and Wu, V.C.H. (2012) A Piezoelectric Immunosensor for Specific Capture and 
Enrichment of Viable Pathogens by Quartz Crystal Microbalance Sensor, Followed by Detection with Antibody-Functionalized Gold Nanoparticles. Biosensors and Bioelectronics, 38, 177-183. http://dx.doi.org/10.1016/j.bios.2012.05.024

[96] www.q-sense.com/file/qcm-d-and-nanoparticles-application-overview.pdf

[97] Crooks, R.M. and Ricco, A.J. (1998) New Organic Materials Suitable for Use in Chemical Sensor Arrays. Accounts of Chemical Research, 31, 219-227.

[98] Ricco, A.J., Crooks, R.M. and Osbourn, G.C. (1998) Surface Acoustic Wave Chemical Sensor Arrays: New Chemically Sensitive Interfaces Combined with Novel Cluster Analysis to Detect Volatile Organic Compounds and Mixtures. Accounts of Chemical Research, 31, 289-296. http://dx.doi.org/10.1021/ar9600749

[99] Kepley, L.J., Crooks, R.M. and Ricco, A.J. (1992) A Selective SAW-Based Organophosphonate Chemical Sensor Employing a Self-Assembled, Composite Monolayer: A New Paradigm for Sensor Design. Analytical Chemistry, 64, 3191-3193. http://dx.doi.org/10.1021/ac00048a018

[100] Schonherr, H., Vancso, G.J., Huisman, B.H., Van Veggel, F.C.J.M. and Reinhoudt, D.N. (1997) An Atomic Force Microscopy Study of Self-Assembled Monolayers of Calix[4]resorcinarene Adsorbates on Au(111). Langmuir, 13, 1567-1570. http://dx.doi.org/10.1021/la9610841

[101] Chen, S., Pei, R., Zhao, T. and Dyer, D.J. (2002) Gold Nanoparticle Assemblies by Metal Ion-Pyridine Complexation and Their Rectified Quantized Charging in Aqueous Solutions. Journal of Physical Chemistry B, 106, 1903-1908. http://dx.doi.org/10.1021/jp013574e

[102] Shen, G., Wang, H., Shen, G. and Yu, R.Q. (2007) Au Nanoparticle Network-Type Thin Films Formed via Mixed Assembling and Cross-Linking Route for Biosensor Application: Quartz Crystal Microbalance Study. Analytical Biochemistry, 365, 1-6. http://dx.doi.org/10.1016/j.ab.2006.11.038

[103] Liu, H. and Hu, N.F. (2006) Interaction between Myoglobin and Hyaluronic Acid in Their Layer-by-Layer Assembly: Quartz Crystal Microbalance and Cyclic Voltammetry Studies. Journal of Physical Chemistry B, 110, 14494-14502. http://dx.doi.org/10.1021/jp061271k

[104] Guleryuz, H., Kaus, I., Buron, C.C., Filiatre, C., Hedin, N., Bergstrom, L. and Einarsrud, M.A. (2014) Deposition of Silica Nanoparticles onto Alumina Measured by Optical Reflectometry and Quartz Crystal Microbalance with Dissipation Techniques. Colloids and Surfaces A: Physicochemical and Engineering Aspects, 443, 384-390. http://dx.doi.org/10.1016/j.colsurfa.2013.11.049 
Scientific Research Publishing (SCIRP) is one of the largest Open Access journal publishers. It is currently publishing more than 200 open access, online, peer-reviewed journals covering a wide range of academic disciplines. SCIRP serves the worldwide academic communities and contributes to the progress and application of science with its publication.

Other selected journals from SCIRP are listed as below. Submit your manuscript to us via either submit@scirp.org or Online Submission Portal.
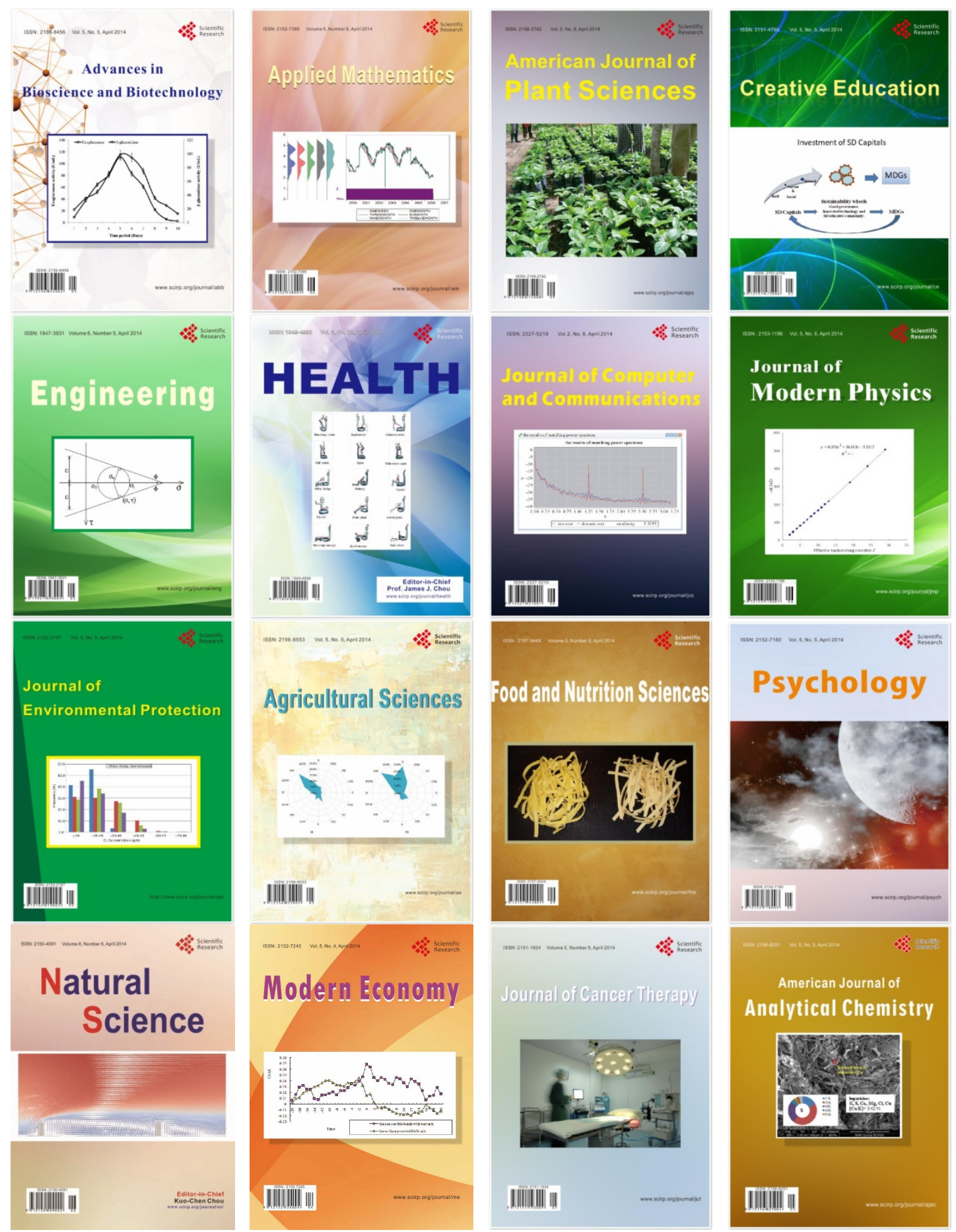